\title{
Design of Hückel-Möbius topological switches with high nonlinear optical properties
}

Miquel Torrent-Sucarrat, ${ }^{1,2,3 *}$ Sara Navarro, ${ }^{4}$ Enrique Marcos, ${ }^{5}$ Josep M. Anglada, ${ }^{6}$ and Josep M. Luis ${ }^{4}$

${ }^{1}$ Department of Organic Chemistry I, Universidad del País Vasco - Euskal Herriko Unibertsitatea (UPV/EHU) and Centro de Innovación en Química Avanzada (ORFEO-CINQA), Manuel Lardizabal Ibilbidea 3, 20018 San Sebastian-Donostia, Spain.

${ }^{2}$ Donostia International Physics Center (DIPC), Manuel Lardizabal Ibilbidea 4, 20018 San Sebastián / Donostia, Spain.

${ }^{3}$ Ikerbasque, Basque Foundation for Science, María Díaz de Haro, 3, 6º 48013 Bilbao, Spain.

${ }^{4}$ Institut de Química Computacional i Catàlisi and Departament de Química, Universitat de Girona, E17071 Girona, Catalonia, Spain.

${ }^{5}$ Institute for Research in Biomedicine (IRB Barcelona), The Barcelona Institute of Science and Technology, Baldiri Reixac 10, 08028 Barcelona, Spain.

${ }^{6}$ Departament de Química Biològica i Modelització Molecular, Institut de Química Avançada de Catalunya (IQAC-CSIC), c/ Jordi Girona 18, E-08034 Barcelona, Spain.

E-mail: miqueltorrentsucarrat@gmail.com

ABSTRACT: The macrocyclic ring of expanded porphyrins presents a conformational versatility that leads to original structural motifs and generates unique Hückel-to-Möbius topological switches. These systems can act as optoelectronic materials and their range of applicability depends on the high values of the nonlinear optical properties (NLOP) and the large differences between the Hückel and Möbius structures. With the aim to design new topological switches with the optimum NLOP, we have performed a DFT computational study on the effect of three different geometric and electronic factors of the meso-substituents: i) their electron-withdrawing and -releasing character; ii) their distribution along 
the porphyrin ring; and iii) the length of the conjugation path. In this work, we report the electronic and vibrational contributions to static and dynamic NLOP of the Hückel and Möbius conformations of 18 meso-substituted [28]-hexaphyrins. These systems can achieve first and second hyperpolarizabilities values around $1 \times 10^{5}$ and $2 \times 10^{7}$ a.u., respectively, and differences between the Möbius and Hückel conformations around $4 \times 10^{4}$ and $5 \times 10^{6}$ a.u., respectively. From our results, we conclude that efficient NLOP topological switches can be obtained from push-pull porphyrins with a $\pi$-conjugated spacer and a strong electron-withdrawing and -releasing groups located on opposite sides of the skeleton ring.

\section{1) INTRODUCTION}

A molecular switch is a molecule that can be interconnected between two or even multiple states in response to external stimuli. ${ }^{1-7}$ The peculiar structural versatility of the expanded porphyrins, such as flexibility of the skeleton ring, metallation, and nature of the meso-substituents, allow them to achieve different conformers. ${ }^{8-12}$ These structures present distinct optical, electronic, and magnetic properties and can be switched between them using chemical and physical modifications (oxidation and reduction, polarity of solvent, temperature, and degree of protonation) or changing the electronic state by photoexcitation (from the ground state to the first singlet and triplet states). ${ }^{13-15}$ Therefore, the expanded porphyrins can be considered as molecular switches.

The first reported dynamic switch between Hückel antiaromatic and Möbius aromatic conformations was reported for A,D-di-p-benzi[28]hexaphyrin(1.1.1.1.1.1) by Latos-Grażyński and coworkers. ${ }^{16}$ In some solvents (alcohols and aliphatic hydrocarbons), only the Hückel structure is observed in the ${ }^{1} \mathrm{H}$ NMR spectrum. On the other hand, in other solvents (in chloroform and N,Ndimethylformamide) the Möbius conformation is the dominant one (an intermediate situation is obtained using dichloromethane and benzene). Moreover, the ratio of the Möbius conformer increases when the temperature decreases. The meso-aryl-substituted [28]hexaphyrins(1.1.1.1.1.1) synthesized by Kim, Osuka, and co-workers also show an equilibrium between several antiaromatic planar Hückel and 
twisted Möbius aromatic structures depending on the environmental conditions and therefore presenting interesting switching features. ${ }^{17-19}$ When the temperature is decreased to $-100^{\circ} \mathrm{C}$ in THF, the Möbius conformation becomes the predominant species. In the solid state, both planar Hückel and twisted Möbius can be obtained depending upon the meso-substituent and crystallization solvent. A similar solvent-dependent switching behavior was found for the meso(heptakis)pentafluorophenyl[32] heptaphyrin. ${ }^{20}$ It is worth noting that intramolecular hydrogen bond interactions between imine-type and amine-type pyrroles $(\mathrm{NH} \cdots \mathrm{N})$ play a crucial role in the relative stability of the expanded porphyrin conformers and, therefore, acid-base reactions can also be used to interconnect different conformers. ${ }^{21-24}$

In the expanded porphyrins, it has been observed a relationship between molecular topology, aromaticity, and two-photon absorption (TPA) properties. Indeed the TPA cross-section values have been used as an approximate experimental measure of aromaticity in macrocyclic $\pi$-conjugated systems. ${ }^{25,26}$ Then, these Hückel-to-Möbius topological switches can also potentially behave as molecular optical switches. ${ }^{27}$ Their range of applicability will be based on the high values of the nonlinear optical properties (NLOP) and the large differences between the Hückel and Möbius structures. For this purpose, it has been well-established in the literature that the computational theoryaided design can be a useful tool to optimize the molecular electro-optic performance. ${ }^{28-44}$

Recently, several works $s^{45-55}$ have evaluated the NLOP of Hückel and Möbius topologies. For instance, the present authors studied the electronic and vibrational contributions to static and dynamic NLOP of the Hückel-Möbius switch of the bianthraquinodimethane modified [16] annulene ${ }^{56,57}$ and A,D-di-p-benzi[28]hexaphyrin(1.1.1.1.1.1). ${ }^{16}$ Our previous results indicated that these systems present high NLOP values and large differences between the Hückel and Möbius structures, pointing out their potential use as optical switches. Kundi et al. ${ }^{53}$ analyzed the gas phase one- and two-photon absorption properties of the first two excited states of the triply twisted Möbius annulene molecule ${ }^{58}$ and five model systems substituted with different donor and acceptor groups using the response theory and two-state model approaches. It was found that the unsubstituted molecule is completely two-photon inactive and it becomes active with the introduction of strong donor-acceptor groups. In 2016, Sun and co-workers ${ }^{54}$ 
studied the electronic polarizability and first hyperpolarizability of five different conformations of [26]hexaphyrin(1.1.1.1.1.1) and their corresponding [28]hexaphyrin structures, concluding that the magnitude of their NLOP depend on the conformer type (i.e. triangular-shape $\beta^{e}<$ eight-shape $\beta^{e}<$ Möbius-shape $\beta^{e}$ ). And very recently, Islam and Lone ${ }^{55}$ computed the electronic NLOP of five octaphyrin derivatives (different meso-susbstituents were considered) with a twisted double-side Hückel topology at CAM-B3LYP level. They concluded that the incorporation of electron-donating groups on the octaphyrin skeleton increases their NLOP.

Herein, we report a theoretical investigation of the electronic and vibrational contributions to static and dynamic NLOP of the Hückel and Möbius conformations of the meso-hexakis(2,6difluorophenyl)[28]hexaphyrin(1.1.1.1.1.1) synthesized by Sankar et $a l .{ }^{17}$ and other seventeen [28]hexaphyrin models (see Schemes 1-5 for their structure and nomenclature used throughout the whole text). In order to understand the main factors that enhance the NLOP of these topological switches, three different factors of the meso-substitutents are studied: i) their electron-withdrawing and releasing character; ii) their distribution along the porphyrin ring; and iii) length of the conjugation path. Additionally, a longer term aim is to guide and motivate experimental research groups that work in this field to synthesize new topological switches with the optimum NLOP.

(Insert Schemes 1-5 around here)

\section{2) COMPUTATIONAL METHODS}

The evaluation of the static electronic contribution to dipole moment, $\mu^{e}$, linear polarizability, $\alpha^{e}$, first hyperpolarizability, $\beta^{e}$, and second hyperpolarizability, $\gamma^{e}$, were performed at the M05-2X $\mathrm{X}^{59}$ and CAM-B3LYP ${ }^{60}$ levels with the 6-31G, 6-311G(d), and 6-31+G basis sets ${ }^{61,62}$ using the GAUSSIAN 09 program package. ${ }^{63}$ All calculations were carried out in the gas phase. In a previous work we investigated the relevance of the solvent effect in the evaluation of the expanded porphyrins NLOP. ${ }^{50}$ However, herein, we wanted to focus on analyzing the effect of the expanded porphyrins meso- 
substituents on the NLOPs. In a similar way to our previous article, ${ }^{50}$ the inclusion of the diffuse functions hindered the self-consistent field convergence. That's why 6-31+G has only been used for one expanded porphyrin to evaluate the basis set convergence. In order to avoid the incorrect electric field dependence of the electronic structure modelled by most of DFT exchange functionals, ${ }^{64-66}$ we used the hybrid M05-2X and long-range corrected CAM-B3LYP functionals. We have previously showed that these two methods provide a semiquantitative description of the NLOPs at a reasonable computational cost for expanded porphryins. ${ }^{49,50}$ Whereas the key of the good performance of M05-2X on the NLOP calculations is the large fraction of exact Hartree-Fock (HF) exchange included by this hybrid functional, the success of CAM-B3LYP is based on introducing a growing fraction of exact HF exchange when the distance between electrons in the electron repulsion operator increases.

$\mu^{e}, \alpha^{e}$, and $\beta^{e}$ were analytically evaluated for all the methodologies. In contrast, $\gamma^{e}$ was obtained by finite field differentiation of $\beta^{e}$. The numerical differentiation was carried out for field strengths of $\pm 0.0002, \pm 0.0004, \pm 0.0008$, and \pm 0.0016 a.u. The smallest field magnitude that produced a stable derivative was selected using a Romberg method triangle. ${ }^{67,68}$ The symmetry restrictions have not been considered in the optimization process and the X-ray structures of $\mathbf{H}_{2,6 F P h}$ and $\mathbf{M}_{2,6} \mathbf{F P h}$ have been used as the initial geometry of the optimization process ${ }^{17}$ (the remaining structures were built from these). The most stable network of intramolecular $\mathrm{NH}^{\cdots} \mathrm{N}$ hydrogen bond interactions between imine-type and amine-type pyrroles was chosen for Hückel and Möbius structures, as shown in our previous study. ${ }^{69,70}$ The average isotropic (hyper)polarizabilities are defined by following equations: ${ }^{.1}$

$$
\begin{gathered}
\bar{\alpha}=\frac{1}{3} \sum_{i=x, y, z} \alpha_{i i}, \\
\bar{\beta}=\frac{1}{5|\bar{\mu}|} \sum_{i, j=x, y, z} \mu_{i}\left(\beta_{i j j}+\beta_{j i j}+\beta_{j j i}\right),
\end{gathered}
$$

and

$$
\bar{\gamma}=\frac{1}{15} \sum_{i, j=x, y, z} \gamma_{i i j j}+\gamma_{i j i j}+\gamma_{i j j i}
$$


In order to simplify the analysis of the results, all discussed NLOP values throughout the whole text are average isotropic (hyper)polarizabilities. Indeed, the main goal of this work is to enhance the NLOP of the studied expanded porphyrin switches with a theory-aided design, and the average isotropic hyperpolarizabilities are the best parameters to measure at molecular level the NLOP.

The vibrational (hyper)polarizabilities can be computed using the perturbation treatment of Bishop and Kirtman $(\mathrm{BK})^{72-74}$ or its variational counterpart based on the analytical response theory proposed by Christiansen et al. ${ }^{75-77}$ One alternative approach to compute the vibrational hyperpolarizabilities that can be linked to the BK method is the nuclear relaxation (NR) approach. ${ }^{78-80}$ The NR method takes into account the effect of the field-induced change of the equilibrium geometry on the molecular energy. ${ }^{78-81}$ In the NR approach, the leading vibrational contributions to NLOP are given by the nuclear relaxation $\left(P^{n r}\right)$ contributions, which arise from the change in the electronic energy caused by the field-induced relaxation of the equilibrium geometry. Higher-order terms, usually smaller than $P^{n r}$ and that are not computed here, come from the field-induced perturbation of the zero-point energy. ${ }^{82,83}$

The infinite optical frequency (IOF) approximation is a very efficient approach to compute the vibrational hyperpolarizabilities at a satisfactory accuracy. ${ }^{84-86}$ It assumes that the optical frequency tend to the infinite limit $(\omega \rightarrow \infty)$, which simplifies the expressions of the dynamic $P^{n r}$ contributions to Pockels $\left(\beta^{n r}(-\omega ; \omega, 0)_{\omega \rightarrow \infty}\right)$, Kerr $\left(\gamma^{n r}(-\omega ; \omega, 0,0)_{\omega \rightarrow \infty}\right)$, field induced second harmonic generation (FISHG, $\left.\quad \gamma^{n r}(-2 \omega ; \omega, \omega, 0)_{\omega \rightarrow \infty}\right)$, and intensity dependent refractive index (IDRI, $\left.\gamma^{n r}(-\omega ; \omega,-\omega, \omega)_{\omega \rightarrow \infty}\right)$ nonlinear optical phenomena. ${ }^{80,81}$

The field-induced vibrational coordinates (FICs) ${ }^{86-89}$ methodology has been used for the analytical calculation of $P^{n r}$. The FICs are defined as the change of the equilibrium geometry caused by static applied field. The FICs radically reduce the number of $n^{\text {th }}$-order derivatives required to compute the nuclear relaxation hyperpolarizabilities. For instance, for evaluating the average value of nuclear relaxation contribution to Kerr effect second hyperpolarizabilities of the expanded porphyrins studied here, using normal modes the number of required third derivatives to be computed is about $5 \times 10^{4}$, whereas using FICs the analytical formulas only involve 9 third derivatives. ${ }^{88}$ 


\section{3) RESULTS AND DISCUSSIONS}

Table 1 contains the electronic and nuclear relaxation static polarizabilities and first and second hyperpolarizabilities, and the IOF approximation to dynamic Pockels, Kerr, FISHG, and IDRI nuclear relaxation hyperpolarizabilities for the Hückel and Möbius structures of meso-hexakis(2,6difluorophenyl)[28]hexaphyrin(1.1.1.1.1.1) $\left(\mathbf{H}_{2,6 \mathbf{F P h}}\right.$ and $\left.\mathbf{M}_{2,6 \mathbf{F P h}}\right)$. The NLOP have been evaluated at CAM-B3LYP and M05-2X levels using the 6-31G, 6-31+G, and 6-311G(d) basis sets. In analogy to our previous work with the A,D-di-p-benzi[28]hexaphyrin(1.1.1.1.1.1), ${ }^{50}$ the agreement between the results obtained with the three basis sets and two DFT methods are good enough for the required accuracy to achieve the main goal of the present study; i.e. for $\bar{\alpha}^{e}$ and $\bar{\gamma}^{e}$ the maximum relative error represents less than $10 \%$ and $20 \%$ of the property, respectively. For the vibrational contribution to static and IOF dynamic molecular NLOP, the selection of the basis and DFT method is slightly more relevant, since the differences lie in the $1 \%-34 \%$ range. The first hyperpolarizabilities of $\mathbf{M}_{2,6 \mathbf{F P h}}$ have not been considered in the previous analysis of the maximum relative errors because this conformation presents very small values, even though the differences for $\bar{\beta}^{e}$ are smaller than $30 \%$. On the basis of these results and in agreement with our previous studies, ${ }^{49,50}$ we can conclude that a semiquantitative picture of the differences between the electronic and vibrational contributions to the NLOP of Hückel and Mobius [28]hexaphyrin conformers can be provided by the CAM-B3LYP/6-31G and M05-2X/6-31G levels of theory with an affordable computational cost.

(Insert Table 1 around here)

Table 1 shows that the vibrational contribution to static and IOF dynamic NLOP can be either larger or comparable in size than the electronic contribution. For instance, at CAM-B3LYP/6-311G(d,p) level for the $\mathbf{M}_{2,6 \mathbf{F P h}}\left(\mathbf{H}_{2,6 \mathbf{F P h}}\right)$ structures the $\bar{\gamma}^{n r}(-\omega ; \omega, 0,0)_{\omega \rightarrow \infty} / \bar{\gamma}^{e}(0 ; 0,0,0)$ and $\bar{\gamma}^{n r}(-\omega ; \omega,-\omega, \omega)_{\omega \rightarrow \infty} / \bar{\gamma}^{e}(0 ; 0,0,0)$ ratios are 0.9 and $2.7(0.7$ and 1.9$)$, respectively. As a consequence, it is necessary to consider the sum of the electronic and vibrational contributions (i.e. $\bar{\alpha}=\bar{\alpha}^{e}+\bar{\alpha}^{n r}$, 
$\bar{\beta}=\bar{\beta}^{e}+\bar{\beta}^{n r}$, and $\bar{\gamma}=\bar{\gamma}^{e}+\bar{\gamma}^{n r}$ ) to reproduce correctly the (hyper)polarizabilities of these aromatic systems. Another important point to address from the results of Table 1 is the high values of NLOP obtained, e.g. the values of $\bar{\gamma}^{e}(0 ; 0,0,0)+\bar{\gamma}^{n r}(-\omega ; \omega, 0,0)_{\omega \rightarrow \infty}$ and $\bar{\gamma}^{e}(0 ; 0,0,0)+$ $\bar{\gamma}^{n r}(-\omega ; \omega,-\omega, \omega)_{\omega \rightarrow \infty}$ are $2.10 \times 10^{6}$ and $3.48 \times 10^{6}$ a.u. $\left(2.51 \times 10^{6}\right.$ and $4.85 \times 10^{6}$ a.u. $)$, respectively, for the $\mathbf{H}_{2,6 \mathbf{6 P h}}\left(\mathbf{M}_{\mathbf{2}, \mathbf{6} \mathbf{F P h}}\right)$ structure at CAM-B3LYP/6-311G(d,p) level. Moreover, important differences are observed between the total $\bar{\beta}$ and $\bar{\gamma}$ of Hückel and Möbius structures. For instance, at CAM-B3LYP/6-311G(d,p) level, the maximum difference between conformers is $1.37 \times 10^{6}$ a.u., measured for $\bar{\gamma}^{e}(0 ; 0,0,0)+\bar{\gamma}^{n r}(-\omega ; \omega,-\omega, \omega)_{\omega \rightarrow \infty}$. Then, we conclude that the [28]-hexaphyrin topological switches present the potential to become optical switches with high NLOP.

The introduction of the FICs has radically reduced the number of first-, second-, and third-order derivatives required to measure the vibrational contribution of the NLOP. Nevertheless, it still implies a considerable computational effort if a large set of systems is studied, e.g. all NR contributions at CAMB3LYP/6-311G(d,p) level of the Hückel and Möbius structures displayed in Table 1 require in total 26 frequency calculations. Nevertheless, the evaluation of $\bar{\alpha}^{n r}(0 ; 0), \bar{\beta}^{n r}(-\omega ; \omega, 0)_{\omega \rightarrow \infty}$, and $\bar{\gamma}^{n r}(-\omega ; \omega,-\omega, \omega)_{\omega \rightarrow \infty}$ requires only a single frequency calculation at the equilibrium geometry. Moreover, the values of $\bar{\gamma}^{n r}(-\omega ; \omega,-\omega, \omega)_{\omega \rightarrow \infty}$ displayed in Table 1 indicate that they can be used as a satisfactory estimation of the magnitude of the vibrational contributions to $\bar{\gamma}$. Then, we can conclude that a semiquantitative description of the magnitude of the total $\bar{\alpha}, \bar{\beta}$, and $\bar{\gamma}$ can be obtained with the evaluation of $\quad \bar{\alpha}^{e}(0 ; 0)+\bar{\alpha}^{n r}(0 ; 0), \quad \bar{\beta}^{e}(0 ; 0,0)+\bar{\beta}^{n r}(-\omega ; \omega, 0)_{\omega \rightarrow \infty}, \quad$ and $\quad \bar{\gamma}^{e}(0 ; 0,0,0)+$ $\bar{\gamma}^{n r}(-\omega ; \omega,-\omega, \omega)_{\omega \rightarrow \infty}$ properties, respectively, at the CAM-B3LYP/6-31G or M05-2X/6-31G levels of theory. Unless indicated otherwise, all the remaining NLOP values discussed in the text have been evaluated using the M05-2X/6-31G methodology.

The NLOP results of [28]-hexaphyrins with hydrogen, fluorine, and methyl as meso-substituents are collected in Table 2 (see Schemes 2 and 3 for the nomenclature used). Four push-pull models with 
different distributions of the $\mathrm{F}$ and $\mathrm{CH}_{3}$ meso-substituents along the expanded porphyrin have also been considered. The first two arrangements (HсH3_F_a, MCH3_F_a, HCH3_F_b, M1CH3_F_b, and M2ch3_F_b structures) only contain one fluorine and one methyl meso-substituent located on opposite sides of the

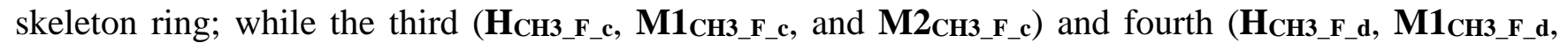
and M2CH3_F_d) distributions present three fluorine and three methyl meso-substituents, and two fluorine and two methyl meso-substituents, respectively. In the three later models, two different Möbius conformers are considered; i.e. in M1 (M2) structure, the twisted side of the Möbius conformation contains the fluorine (methyl) meso-substituents.

(Insert Table 2 around here)

The replacement of the 2,6-difluorophenyl with hydrogen as meso-substituent implies a reduction of NLOP values by a factor ca. 2. It is pertinent to note that the NLOP values of $\mathbf{H}_{\mathbf{H}}$ and $\mathbf{M}_{\mathbf{H}}$ will represent our reference model. The $\bar{\gamma}$ values of the Hückel (Möbius) structures with methyl and fluorine groups as meso-substituents are slightly larger than the $\mathbf{H}_{\mathbf{H}}\left(\mathbf{M}_{\mathbf{H}}\right)$ ones. The maximum $\bar{\gamma}$ value is $2.82 \times$ $10^{6}$ a.u. $\left(5.92 \times 10^{5}+2.23 \times 10^{6}\right.$ a.u. $)$ and it has been obtained for the McH3 structure. All the topological switches of Table 2 present important $\bar{\gamma}$ differences between Hückel and Möbius structures,

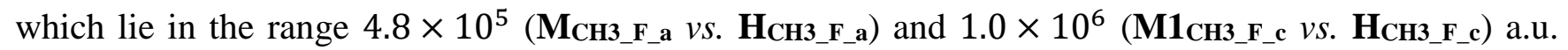
The latter difference value implies $c a$. 60\% of $\bar{\gamma}$ HCH3_F_c, emphasizing its potential as optical switches. The first hyperpolarizability presents large differences between Hückel and Möbius conformers (three orders of magnitude), mainly because most of the Hückel conformations present small or null (by

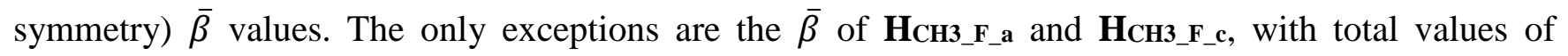
$2.40 \times 10^{3}$ and $1.50 \times 10^{3}$ a.u., respectively. The $\mathbf{M 1} \mathbf{C H}_{\mathbf{C} \text { _F_c }}$ structure shows the maximum $\bar{\beta}$ value of Table 2 with $6.21 \times 10^{3}$ a.u. Among the four push-pull models with different distributions of the $\mathrm{F}$ and $\mathrm{CH}_{3}$ meso-substituents, the Hückel (Möbius) structures present similar NLOP values and also similar NLOP differences between the Hückel and Möbius conformers. Therefore, the number of the methyl 
and fluorine meso-substituents in the porphyrin ring shows a minor role in the NLOP enhancement of these topological switches.

The methyl and fluorine groups have weak electron-withdrawing and -releasing character, respectively, and in consequence, they only provoke small modifications in the response to an external electric field of the expanded porphyrin ring. Then, the next step was to consider the same four pushpull models, but with a strong electron-withdrawing and -releasing character such as nitro and amino groups, respectively. The NLOP results of these Hückel and Mobius conformers are collected in Table 3. An important increase of the optical response properties is observed in the four topological switches

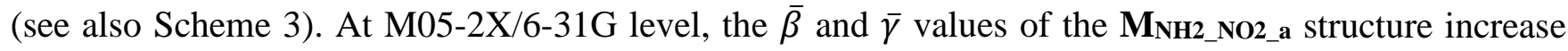
about 16.0 and 1.6 times, respectively, with respect to their counterparts for $\mathbf{M}_{\mathbf{H}}$. Then, we conclude that to achieve the NLOP enhancement of this type of porphyrin ring it is more important the nature of the meso-substituents than their number. According to the results of Table 3, the $\bar{\beta}(\bar{\gamma})$ values range from $-2.65 \times 10^{3}\left(1.42 \times 10^{6}\right)$ to $2.47 \times 10^{4}\left(4.10 \times 10^{6}\right)$ a.u. For $\mathbf{H}_{\mathbf{N H 2} \text { _NO2_a }}$ and $\mathbf{M}_{\mathbf{N H 2} \_N O 2 \_a}$, the nonlinear optical properties have also been evaluated at M05-2X/6-311G(d) level and comparable results have been obtained, being the differences of $\bar{\beta}$ and $\bar{\gamma}$ between the two basis sets used, 6-31G and 6-311G(d), smaller than 30\%.

(Insert Table 3 around here)

Similarly to the results displayed above, important $\bar{\beta}$ and $\bar{\gamma}$ differences (ca. $1 \times 10^{4}$ and $1 \times 10^{6}$ a.u., respectively) between Hückel and Möbius structures are found in Table 3. In addition, it is important to remark that $\mathbf{M 1}$ and $\mathbf{M} 2$ conformers also present non-negligible differences, which open up a wide array of options for the possibility of a three-level optical switching. For example, the $\bar{\gamma}(\bar{\beta})$ values of the HNH2_NO2_c, M1NH2_NO2_c, and M2NH2_NO2_c structures are $2.37 \times 10^{6}, 1.92 \times 10^{6}$, and $3.70 \times 10^{6}$ a.u. $\left(3.92 \times 10^{3}, 5.00 \times 10^{3}\right.$, and $1.10 \times 10^{4}$ a.u. $)$, respectively. Therefore, a push-pull 
model with strong electron-withdrawing and -releasing groups located on opposite sides of the expanded porphyrin allows designing an efficient Hückel-Möbius topological switch.

In order to enhance even more the NLOP performance of these [28]-hexaphyrins, it has been considered four different $\pi$-conjugated links (p-phenylene, phenyl acetylene, pyrrole, and pyrrole acetylene) between the amino and nitro groups and the expanded porphyrin (see Schemes 4 and 5). According to the above results, only two meso-substituents (one with electron-withdrawing character and the other with electron-releasing character) have been added in the skeleton ring. In Table 4, one can see that the introduction of $\pi$-conjugated spacers provokes an important enlargement of the NLOP values and also their corresponding differences between Hückel and Möbius structures. For each pphenylene, pyrrole, and acetylenes units added as bridges, $\bar{\beta}$ and $\bar{\gamma}$ values increase around $100 \%$. For instance, in the MCCPhNH2_CCPhNO2_a structure, the obtained $\bar{\beta}$ and $\bar{\gamma}$ results imply an increment about 62 and 10 times, respectively, with respect to $\mathbf{M}_{\mathbf{H}}$ ones. Moreover, the $\bar{\beta}$ and $\bar{\gamma}$ differences between MCCPhNH2_CCPhNO2_a and HCCPhNH2_CCPhNO2_a conformers are $3.49 \times 10^{4}$ and $5.62 \times 10^{6}$ a.u., respectively, whose values represent an increase by factors $c a .23$ and 7, respectively, with respect to the differences obtained for $\mathbf{M}_{\mathbf{H}}$ and $\mathbf{H}_{\mathbf{H}}$.

In Table 4, the $\bar{\beta}(\bar{\gamma})$ values range from $1.36 \times 10^{4}\left(4.84 \times 10^{6}\right)$ to $9.54 \times 10^{4}\left(2.06 \times 10^{7}\right)$ a.u. and the $\bar{\beta}(\bar{\gamma})$ differences between Hückel and Möbius structures range from $3.98 \times 10^{3}\left(1.43 \times 10^{6}\right)$ to $4.76 \times 10^{4}\left(7.12 \times 10^{6}\right)$ a.u. Finally, in the expanded models with the possibility of two different Möbius conformers, it is worth noting that relevant NLOP variations also are found between them. For example, the $\bar{\gamma}(\bar{\beta})$ values of the HCCPhNH2_CCPhNO2_b, M1CCPhNH2_CCPhNO2_b, and M2CCPhNH2_CCPhNO2_b structures are $1.08 \times 10^{7}, 8.67 \times 10^{6}$, and $1.38 \times 10^{7}$ a.u. $\left(4.72 \times 10^{4}, 3.10 \times 10^{4}\right.$, and $5.12 \times 10^{4}$ a.u.), respectively.

(Insert Table 4 around here) 
Last but not least, it is worth mentioning that for most of the topological switches here studied the energetic difference between the Hückel and Möbius conformers is quite small, ca. $3 \mathrm{kcal} / \mathrm{mol}$, and highly dependent on the meso-substituent, as shown previously. ${ }^{70}$ This indicates that small energetic variations in these expanded porphyrins can induce important changes in their topological and optical properties.

\section{4) SUMMARY AND CONCLUSIONS}

In this work, we have performed a theoretical study of the electronic and vibrational contributions to static and dynamic NLOP of the Hückel and Möbius conformations of the meso-hexakis(2,6difluorophenyl)[28]hexaphyrin(1.1.1.1.1.1) synthesized by Sankar et al. ${ }^{17}$ and seventeen [28]hexaphyrin models. With the aim of exploring the applicability of these molecules as optical switches and understanding the main factors that enhance the NLOP of these topological switches, the effect of three different factors of the meso-substituents were studied: i) their electron-withdrawing or electron releasing character; ii) their distribution along the porphyrin ring; and iii) length of the conjugation path. The results highlight the following points:

a) With an affordable computational cost, a semiquantitative description of the magnitude of the total $\bar{\alpha}, \bar{\beta}$, and $\bar{\gamma}$ can be obtained with the evaluation of $\bar{\alpha}^{e}(0 ; 0)+\bar{\alpha}^{n r}(0 ; 0), \bar{\beta}^{e}(0 ; 0,0)+$ $\bar{\beta}^{n r}(-\omega ; \omega, 0)_{\omega \rightarrow \infty}$, and $\bar{\gamma}^{e}(0 ; 0,0,0)+\bar{\gamma}^{n r}(-\omega ; \omega,-\omega, \omega)_{\omega \rightarrow \infty}$ properties, respectively, at the CAM-B3LYP/6-31G or M05-2X/6-31G levels of theory.

b) For the NLOP enhancement of these topological switches, it is more important the electronic nature of the meso-substituent (i.e. electron-releasing or electron-withdrawing) than the number of meso-substituents in the porphyrin ring.

c) To obtain an expanded porphyrin switch with high NLOP values and important NLOP differences between the different conformers, it is requested to design a push-pull molecule, 
with meso-substituents containing a $\pi$-conjugated link and strong electron-withdrawing and releasing groups located on opposite sides of the skeleton ring.

d) The meso-substituted [28]-hexaphyrins can achieve $\bar{\beta}$ and $\bar{\gamma}$ values around $1 \times 10^{5}$ and $2 \times$ $10^{7}$ a.u., respectively, and differences between the Möbius and Hückel conformations around $4 \times 10^{4}$ and $5 \times 10^{6}$ a.u., respectively. Therefore, due to these large differences between the NLOPs of the Möbius and Hückel conformations, these expanded porphyrins are excellent candidates to design new efficient NLOP topological switches.

To conclude, we expect that the theoretical results and conclusions presented in this paper will motivate the experimental research groups that work in this field to synthesize new topological switches with optimum NLOP based on the meso-substituted [28]-hexaphyrins studied here.

ACKNOWLEDGMENTS: The calculations described in this work were carried out at the Consorci de Serveis Universitaris de Catalunya (CSUC), SGI/IZO-SGIker, and DIPC. Financial support was provided by the Ministerio de Economía y Competitividad (MINECO) of Spain and FEDER (projects CTQ2016-80375-P and CTQ2014-52525-P) and the Generalitat de Catalunya (Grant 2014SGR139).

\section{References}

(1) Feringa, B. L.; van Delden, R. A.; Koumura, N.; Geertsema, E. M. Chiroptical molecular switches, Chem. Rev., 2000, 100, 1789-1816.

(2) Kottas, G. S.; Clarke, L. I.; Horinek, D.; Michl, J. Artificial molecular rotors, Chem. Rev., 2005, 105, 1281-1376.

(3) Wu, S. W.; Ogawa, N.; Ho, W. Atomic-scale coupling of photons to single-molecule junctions, Science, 2006, 312, 1362-1365.

(4) Liljeroth, P.; Repp, J.; Meyer, G. Current-induced hydrogen tautomerization and conductance switching of naphthalocyanine molecules, Science, 2007, 317, 1203-1206. 
(5) Kay, E. R.; Leigh, D. A.; Zerbetto, F. Synthetic molecular motors and mechanical machines, Angew. Chem., Int. Ed., 2007, 46, 72-191.

(6) Wang, Y. F.; Kroger, J.; Berndt, R.; Hofer, W. A. Pushing and Pulling a Sn Ion through an Adsorbed Phthalocyanine Molecule, J. Am. Chem. Soc., 2009, 131, 3639-3643.

(7) Szymanski, W.; Beierle, J. M.; Kistemaker, H. A. V.; Velema, W. A.; Feringa, B. L. Reversible Photocontrol of Biological Systems by the Incorporation of Molecular Photoswitches, Chem. Rev., 2013, 113, 6114-6178.

(8) Osuka, A.; Saito, S. Expanded porphyrins and aromaticity, Chem. Commun., 2011, 47, 4330-4339.

(9) Shin, J. Y.; Kim, K. S.; Yoon, M. C.; Lim, J. M.; Yoon, Z. S.; Osuka, A.; Kim, D. Aromaticity and photophysical properties of various topology-controlled expanded porphyrins, Chem. Soc. Rev., 2010, 39, 2751-2767.

(10) Saito, S.; Osuka, A. Expanded Porphyrins: Intriguing Structures, Electronic Properties, and Reactivities, Angew. Chem., Int. Ed., 2011, 50, 4342-4373.

(11) Stepień, M.; Sprutta, N.; Latos-Grażyński, L. Figure Eights, Mobius Bands, and More: Conformation and Aromaticity of Porphyrinoids, Angew. Chem., Int. Ed., 2011, 50, 4288-4340.

(12) Mack, J. Expanded, Contracted, and Isomeric Porphyrins: Theoretical Aspects, Chem. Rev., 2017, 117, 3444-3478.

(13) Szyszko, B.; Bialek, M. J.; Pacholska-Dudziak, E.; Latos-Grazynski, L. Flexible Porphyrinoids, Chem. Rev., 2017, 117, 2839-2909.

(14) Sung, Y. M.; Oh, J.; Cha, W. Y.; Kim, W.; Lim, J. M.; Yoon, M. C.; Kim, D. Control and Switching of Aromaticity in Various All-Aza-Expanded Porphyrins: Spectroscopic and Theoretical Analyses, Chem. Rev., 2017, 117, 2257-2312.

(15) Tanaka, T.; Osuka, A. Conjugated porphyrin arrays: synthesis, properties and applications for functional materials, Chem. Soc. Rev., 2017, 44, 943-969.

(16) Stepień, M.; Latos-Grażyński, L.; Sprutta, N.; Chwalisz, P.; Szterenberg, L. Expanded porphyrin with a split personality: A Huckel-Mobius aromaticity switch, Angew. Chem., Int. Ed., 2007, 46, 7869-7873.

(17) Sankar, J.; Mori, S.; Saito, S.; Rath, H.; Suzuki, M.; Inokuma, Y.; Shinokubo, H.; Kim, K. S.; Yoon, Z. S.; Shin, J. Y.; Lim, J. M.; Matsuzaki, Y.; Matsushita, O.; Muranaka, A.; Kobayashi, N.; Kim, D.; Osuka, A. Unambiguous identification of Mobius aromaticity for meso-Aryl-substituted [28]hexaphyrins(1.1.1.1.1.1), J. Am. Chem. Soc., 2008, 130, 13568-13579.

(18) Kim, K. S.; Yoon, Z. S.; Ricks, A. B.; Shin, J. Y.; Mori, S.; Sankar, J.; Saito, S.; Jung, Y. M.; Wasielewski, M. R.; Osuka, A.; Kim, D. Temperature-Dependent Conformational Change of meso- 
Hexakis(pentafluorophenyl) [28]Hexaphyrins(1.1.1.1.1.1) into Mobius Structures, J. Phys. Chem. A, 2009, 113, 4498-4506.

(19) Yoon, M. C.; Kim, P.; Yoo, H.; Shimizu, S.; Koide, T.; Tokuji, S.; Saito, S.; Osuka, A.; Kim, D. Solvent- and Temperature-Dependent Conformational Changes between Huckel Antiaromatic and Mobius Aromatic Species in meso-Trifluoromethyl Substituted [28]Hexaphyrins, J. Phys. Chem. B, 2011, 115, 14928-14937.

(20) Yoon, M. C.; Shin, J. Y.; Lim, J. M.; Saito, S.; Yoneda, T.; Osuka, A.; Kim, D. SolventDependent Aromatic versus Antiaromatic Conformational Switching in meso(Heptakis)pentafluorophenyl [32]Heptaphyrin, Chem.-Eur. J., 2011, 17, 6707-6715.

(21) Saito, S.; Shin, J. Y.; Lim, J. M.; Kim, K. S.; Kim, D.; Osuka, A. Protonation-Triggered Conformational Changes to Mobius Aromatic [32]Heptaphyrins(1.1.1.1.1.1.1), Angew. Chem., Int. Ed., 2008, 47, 9657-9660.

(22) Lim, J. M.; Shin, J. Y.; Tanaka, Y.; Saito, S.; Osuka, A.; Kim, D. Protonated [4n]pi and [4n+2]pi Octaphyrins Choose Their Mobius/Huckel Aromatic Topology, J. Am. Chem. Soc., 2010, 132, 3105-3114.

(23) Stepień, M.; Szyszko, B.; Latos-Grażyński, L. Three-Level Topology Switching in a Molecular Mobius Band, J. Am. Chem. Soc., 2010, 132, 3140-3152.

(24) Ishida, S.; Higashino, T.; Mori, S.; Mori, H.; Aratani, N.; Tanaka, T.; Lim, J. M.; Kim, D.; Osuka, A. Diprotonated [28] Hexaphyrins(1.1.1.1.1.1): Triangular Antiaromatic Macrocycles, Angew. Chem., Int. Ed., 2014, 53, 3427-3431.

(25) Lim, J. M.; Yoon, Z. S.; Shin, J. Y.; Kim, K. S.; Yoon, M. C.; Kim, D. The photophysical properties of expanded porphyrins: relationships between aromaticity, molecular geometry and non-linear optical properties, Chem. Commun., 2009, , 261-273.

(26) Yoon, Z. S.; Kwon, J. H.; Yoon, M. C.; Koh, M. K.; Noh, S. B.; Sessler, J. L.; Lee, J. T.; Seidel, D.; Aguilar, A.; Shimizu, S.; Suzuki, M.; Osuka, A.; Kim, D. Nonlinear optical properties and excited-state dynamics of highly symmetric expanded porphyrins, J. Am. Chem. Soc., 2006, 128, 1412814134.

(27) Castet, F.; Rodriguez, V.; Pozzo, J. L.; Ducasse, L.; Plaquet, A.; Champagne, B. Design and characterization of molecular nonlinear optical switches, Acc. Chem. Res., 2013, 46, 2656-2665.

(28) Champagne, B.; Bulat, F. A.; Yang, W. T.; Bonness, S.; Kirtman, B. Density functional theory investigation of the polarizability and second hyperpolarizability of polydiacetylene and polybutatriene chains: Treatment of exact exchange and role of correlation, J. Chem. Phys., 2006, 125, 194114. 
(29) Champagne, B.; Spassova, M. Theoretical investigation on the polarizability and second hyperpolarizability of polysilole, Chem. Phys. Lett., 2009, 471, 111-115.

(30) Kirtman, B.; Bonness, S.; Ramirez-Solis, A.; Champagne, B.; Matsumoto, H.; Sekino, H. Calculation of electric dipole (hyper)polarizabilities by long-range-correction scheme in density functional theory: A systematic assessment for polydiacetylene and polybutatriene oligomers, J. Chem. Phys., 2008, 128, 114108.

(31) Loboda, O.; Zalesny, R.; Avramopoulos, A.; Luis, J. M.; Kirtman, B.; Tagmatarchis, N.; Reis, H.; Papadopoulos, M. G. Linear and Nonlinear Optical Properties of [60]Fullerene Derivatives, $J$. Phys. Chem. A, 2009, 113, 1159-1170.

(32) Yoneda, K.; Nakano, M.; Fukui, H.; Minami, T.; Shigeta, Y.; Kubo, T.; Botek, E.; Champagne, B. Open-Shell Characters and Second Hyperpolarizabilities of One-Dimensional Graphene Nanoflakes Composed of Trigonal Graphene Units, Chemphyschem, 2011, 12, 1697-1707.

(33) Reis, H.; Loboda, O.; Avramopoulos, A.; Papadopoulos, M. G.; Kirtman, B.; Luis, J. M.; Zalesny, R. Electronic and Vibrational Linear and Nonlinear Polarizabilities of Li@C-60 and [Li@C60](+), J. Comput. Chem., 2011, 32, 908-914.

(34) Skwara, B.; Gora, R. W.; Zalesny, R.; Lipkowski, P.; Bartkowiak, W.; Reis, H.; Papadopoulos, M. G.; Luis, J. M.; Kirtman, B. Electronic Structure, Bonding, Spectra, and Linear and Nonlinear Electric Properties of Ti@C-28, J. Phys. Chem. A, 2011, 115, 10370-10381.

(35) Garcia-Borras, M.; Solà, M.; Luis, J. M.; Kirtman, B. Electronic and Vibrational Nonlinear Optical Properties of Five Representative Electrides, J. Chem. Theory Comput., 2012, 8, 2688-2697.

(36) Koukaras, E. H.; Zdetsis, A. D.; Karamanis, P.; Pouchan, C.; Avramopoulos, A.; Papadopoulos, M. G. Structural and Static Electric Response Properties of highly symmetric lithiated silicon cages: theoretical predictions, J. Comput. Chem., 2012, 33, 1068-1079.

(37) Karamanis, P.; Pouchan, C. Second-hyperpolarizability (gamma) enhacement in metaldecorated zizag graphene flakes and ribbos: the size effect, J. Phys. Chem. C, 2013, 117, 3134-3140.

(38) Johnson, L. E.; Dalton, L. R.; Robinson, B. H. Optimizing calculations of electronic excitations and relative hyperpolarizabilities of electrooptic chromophores, Acc. Chem. Res., 2014, 47, 3258-3265.

(39) Karamanis, P.; Otero, N.; Pouchan, C.; Torres, J. J.; Tiznado, W.; Avramopoulos, A.; Papadopoulos, M. G. Significant nonlinear-optical switching capacity in Atomic Clusters built from Silicon and Lithium: A combined ab initio and density functional study, J. Comput. Chem., 2014, 35, 829-838. 
(40)

Bondu, F.; Quertinmont, J.; Rodriguez, V.; Pozzo, J. L.; Plaquet, A.; Champagane, B.;

Castet, F. Second-Order Nonlinear Optical Properties of a Dithienylethene-Indolinooxazolidine Hybrid: A Joint Experimental and Theoretical Investigation, Chem. Eur. J., 2015, 21, 18749-18757.

(41) Beaujean, P.; Bondu, F.; Plaquet, A.; Garcia-Amorós, J.; Cusido, J.; Raymo, F. M.; Castet, F.; Rodriguez, V.; Champagane, B. Oxazines: A New Class of Second-Order Nonlinear Optical Switches, J. Am. Chem. Soc., 2016, 138, 5052-5062.

(42) Nakano, M.; Fukuda, K.; Champagane, B. Third-Order Nonlinear Optical Properties of Asymmetric Non-Alternant Open-Shell Condensed-Ring Hydrocarbons: Effects of Diradical Character, Asymmetricity, and Exchange Interaction, J. Phys. Chem. C, 2016, 120, 1193-1207.

(43) Avramopoulos, A.; Reis, H.; Otero, N.; Karamanis, P.; Pouchan, C.; Papadopoulos, M. G. A Series of Novel Derivatives with Giant Second Hyperpolarizabilities, Based on Radiaannulenes, Tetrathiafulvalene, Nickel Dithiolene, and Their Lithiated Analogues, J. Phys. Chem. C, 2016, 120, 9419-9435.

(44) Pielak, K.; Bondu, F.; Sanguinet, L.; Rodriguez, V.; Champagane, B.; Castet, F. SecondOrder Nonlinear Optical Properties of Multiaddressable Indolinooxazolidine Derivatives: Joint Computational and Hyper-Rayleigh Scattering Investigations, J. Phys. Chem. C, 2017, 121, 1851-1860.

(45) Xu, H. L.; Li, Z. R.; Wang, F. F.; Wu, D.; Harigaya, K.; Gu, F. L. What is the shape effect on the (hyper) polarizabilities? A comparison study on the Mobius, normal cyclacene, and linear nitrogen-substituted strip polyacenes, Chem. Phys. Lett., 2008, 454, 323-326.

(46) Xu, H. L.; Li, Z. R.; Su, Z. M.; Muhammad, S.; Gu, F. L.; Harigaya, K. Knot-Isomers of Mobius Cyclacene: How Does the Number of Knots Influence the Structure and First Hyperpolarizability?, J. Phys. Chem. C, 2009, 113, 15380-15383.

(47) Wang, Y. F.; Li, Z.; Li, Y.; Li, Z. R.; Li, Z. J.; Wu, D.; Ma, F.; Sun, C. C. Mobius basket molecule: structure and properties, Phys. Chem. Chem. Phys., 2010, 12, 8847-8855.

(48) Wang, Y. F.; Wang, Y.; Li, Z. R.; Li, Z.; Xu, H. L.; Sun, C. C. The Lithium-Orientation Effect on the Hyperpolarizability in the Short Zigzag-Edged Monolithiated Aza-Mobius Graphene Ribbon [2,7] Isomers, Int. J. Quantum Chem., 2011, 111, 2406-2415.

(49) Torrent-Sucarrat, M.; Anglada, J. M.; Luis, J. M. Evaluation of the Nonlinear Optical Properties for Annulenes with Huckel and Mobius Topologies, J. Chem. Theory Comput., 2011, 7, 3935-3943.

(50) Torrent-Sucarrat, M.; Anglada, J. M.; Luis, J. M. Evaluation of the nonlinear optical properties for an expanded porphyrin Huckel-Mobius aromaticity switch, J. Chem. Phys., 2012, 137, 184306. 
(51) Gao, Y.; Xu, H. L.; Zhong, R. L.; Sun, S. L.; Su, Z. M. Probing the Relationship between Spin Contamination and First Hyperpolarizability: Open-Shell M_obius Anion, Int. J. Quantum Chem., 2014, 114, 720-724.

(52) Gao, Y.; Xu, H. L.; Zhong, R. L.; Sun, S. L.; Su, Z. M. Structures and electro-optical properties of Mobius [n] Cyclacenes[13-18]: a theoretical study, J. Mol. Model., 2014, 20, 2201.

(53) Kundi, V.; Alam, M. M.; Thankachan, P. P. Triply twisted Mobius annulene: a new class of two-photon active material - a computational study, Phys. Chem. Chem. Phys., 2015, 17, 6827-6833.

(54) Sun, G.; Lei, E.; Liu, X. S.; Yu, C. H.; Duan, X. X.; Liu, C. G. Theoretical investigation of structure diversity and electronic properties in the series isomeric [26]hexaphyrin (1.1.1.1.1.1) and [28]hexaphyrin (1.1.1.1.1.1), Comp. Theor. Chem., 2016, 1087, 18-25.

(55) Islam, N.; Lone, I. H. Computational Studies on Optoelectronic and Nonlinear Properties of Octaphyrin Derivatives, Front. Chem., 2017, 5, 11.

(56) Ajami, D.; Oeckler, O.; Simon, A.; Herges, R. Synthesis of a Mobius aromatic hydrocarbon, Nature, 2003, 426, 819-821.

(57) Ajami, D.; Hess, K.; Kohler, F.; Nather, C.; Oeckler, O.; Simon, A.; Yamamoto, C.; Okamoto, Y.; Herges, R. Synthesis and properties of the first Mobius annulenes, Chem.-Eur. J., 2006, $12,5434-5445$

(58) Schaller, G. R.; Topic, F.; Rissanen, K.; Okamoto, Y.; Shen, J.; Herges, R. Design and synthesis of the first triply twisted Möbius annulene, Nature Chem., 2014, 6, 608-613.

(59) Zhao, Y.; Schultz, N. E.; Truhlar, D. G. Design of density functionals by combining the method of constraint satisfaction with parametrization for thermochemistry, thermochemical kinetics, and noncovalent interactions, J. Chem. Theory Comput., 2006, 2, 364-382.

(60) Yanai, T.; Tew, D. P.; Handy, N. C. A new hybrid exchange-correlation functional using the Coulomb-attenuating method (CAM-B3LYP), Chem. Phys. Lett., 2004, 393, 51-57.

(61) Hehre, W. J.; Ditchfield, R.; Pople, J. A. Self-Consistent Molecular Orbital Methods. XII. Further Extensions of Gaussian-Type Basis Sets for Use in Molecular Orbital Studies of Organic Molecules (6-31G* basis set), J. Chem. Phys., 1972, 56, 2257-2261.

(62) Hehre, W. J.; Radom, L.; Schleyer, P. v. R.; Pople, J. A. Ab Initio Molecular Orbital Theory; Wiley: New York, 1986.

(63) Gaussian 09, Revision B.1, M. J. Frisch; G. W. Trucks; H. B. Schlegel; G. E. Scuseria; M. A. Robb; J. R. Cheeseman; G. Scalmani; V. Barone; B. Mennucci; G. A. Petersson et al., Gaussian, Inc., Wallingford CT, 2009.

(64) Champagne, B.; Perpete, E. A.; van Gisbergen, S. J. A.; Baerends, E. J.; Snijders, J. G.; Soubra-Ghaoui, C.; Robins, K. A.; Kirtman, B. Assessment of conventional density functional schemes 
for computing the polarizabilities and hyperpolarizabilities of conjugated oligomers: An ab initio investigation of polyacetylene chains, J. Chem. Phys., 1998, 109, 10489-10498.

(65) van Gisbergen, S. J. A.; Schipper, P. R. T.; Gritsenko, O. V.; Baerends, E. J.; Snijders, J. G.; Champagne, B.; Kirtman, B. Electric field dependence of the exchange-correlation potential in molecular chains, Phys. Rev. Lett., 1999, 83, 694-697.

(66) Champagne, B.; Perpete, E. A.; Jacquemin, D.; van Gisbergen, S. J. A.; Baerends, E. J.; Soubra-Ghaoui, C.; Robins, K. A.; Kirtman, B. Assessment of conventional density functional schemes for computing the dipole moment and (hyper)polarizabilities of push-pull pi-conjugated systems, $J$. Phys. Chem. A, 2000, 104, 4755-4763.

(67) Davis, P. J.; Rabinowitz, P. In Numerical Integration; Blasdell: London, 1967, p 166.

(68) Champagane, B.; Kirtman, N. In Handbook of Advanced Electronic and Photonic Materials; Nalwas, H. S., Ed.; Academic: San Diego, 2001; Vol. 9, p 63.

(69) Marcos, E.; Anglada, J. M.; Torrent-Sucarrat, M. Theoretical Study of the Switching between Huckel and Mobius Topologies for Expanded Porphyrins, J. Phys. Chem. C, 2012, 116, 2435824366.

(70) Marcos, E.; Anglada, J. M.; Torrent-Sucarrat, M. Effect of the Meso-Substituent in the Huckel-to-Mobius Topological Switches, J. Org. Chem., 2014, 79, 5036-5046.

(71) Bishop, D. M.; Norman, P. In Handbook of Advanced Electronic and Photonic Materials; Nalwas, H. S., Ed.; Academic: San Diego, 2001; Vol. 9, p 1.

(72) Bishop, D. M.; Kirtman, B. A perturbation method for calculating vibrational dynamic dipole polarizabilities and hyperporlarizabilities, J. Chem. Phys., 1991, 95, 2646-2658.

(73) Bishop, D. M.; Kirtman, B. Compact formulas for vibrational dynamic dipole polarizabilities and hyperpolarizabilities, J. Chem. Phys., 1992, 97, 5255-5256.

(74) Bishop, D. M.; Luis, J. M.; Kirtman, B. Additional compact formulas for vibrational dynamic dipole polarizabilities and hyperpolarizabilities, J. Chem. Phys., 1998, 108, 10013-10017.

(75) Christiansen, O. Response theory for vibrational wave functions, J. Chem. Phys., 2005, 122, 194105.

(76) Christiansen, O.; Kongsted, J.; Paterson, M. J.; Luis, J. M. Linear response functions for a vibrational configuration interaction state, J. Chem. Phys., 2006, 125, 214309.

(77) Hansen, M. B.; Christiansen, O. Vibrational contributions to cubic response functions from vibrational configuration interaction response theory, J. Chem. Phys., 2011, 135, 154107.

(78) Luis, J. M.; Duran, M.; Andres, J. L. A systematic and feasible method for computing nuclear contributions to electrical properties of polyatomic molecules, J. Chem. Phys., 1997, 107, 15011512. 
(79) Kirtman, B.; Luis, J. M.; Bishop, D. M. Simple finite field method for calculation of static and dynamic vibrational hyperpolarizabilities: Curvature contributions, J. Chem. Phys., 1998, 108, 10008-10012.

(80) Luis, J. M.; Marti, J.; Duran, M.; Andres, J. L.; Kirtman, B. Nuclear relaxation contribution to static and dynamic (infinite frequency approximation) nonlinear optical properties by means of electrical property expansions: Application to HF, CH4, CF4, and SF6, J. Chem. Phys., 1998, 108, 4123-4130.

(81) Bishop, D. M.; Hasan, M.; Kirtman, B. A simple method for determining approximate static and dynamic vibrational hyperpolarizabilities, J. Chem. Phys., 1995, 103, 4157-4159.

(82) Torrent-Sucarrat, M.; Solà, M.; Duran, M.; Luis, J. M.; Kirtman, B. Initial convergence of the perturbation series expansion for vibrational nonlinear optical properties, J. Chem. Phys., 2002, 116, 5363-5373.

(83) Torrent-Sucarrat, M.; Solà, M.; Duran, M.; Luis, J. M.; Kirtman, B. Basis set and electron correlation effects on initial convergence for vibrational nonlinear optical properties of conjugated organic molecules, J. Chem. Phys., 2004, 120, 6346-6355.

(84) Bishop, D. M.; Dalskov, E. K. Analysis of the vibrational, static and dynamic, second hyperpolarizability of five small molecules, J. Chem. Phys., 1996, 104, 1004-1011.

(85) Quinet, O.; Champagne, B. Vibrational second hyperpolarizability of CH4-nFn molecules with n=0-4, J. Chem. Phys., 1998, 109, 10594-10602.

(86) Luis, J. M.; Duran, M.; Kirtman, B. Field-induced coordinates for the determination of dynamic vibrational nonlinear optical properties, J. Chem. Phys., 2001, 115, 4473-4483.

(87) Luis, J. M.; Duran, M.; Andres, J. L.; Champagne, B.; Kirtman, B. Finite field treatment of vibrational polarizabilities and hyperpolarizabilities: On the role of the Eckart conditions, their implementation, and their use in characterizing key vibrations, J. Chem. Phys., 1999, 111, 875-884.

(88) Luis, J. M.; Duran, M.; Champagne, B.; Kirtman, B. Determination of vibrational polarizabilities and hyperpolarizabilities using field-induced coordinates, J. Chem. Phys., 2000, 113, 5203-5213.

(89) Luis, J. M.; Champagne, B.; Kirtman, B. Calculation of static zero-point vibrational averaging corrections and other vibrational curvature contributions to polarizabilities and hyperpolarizabilities using field-induced coordinates, Int. J. Quantum Chem., 2000, 80, 471-479. 


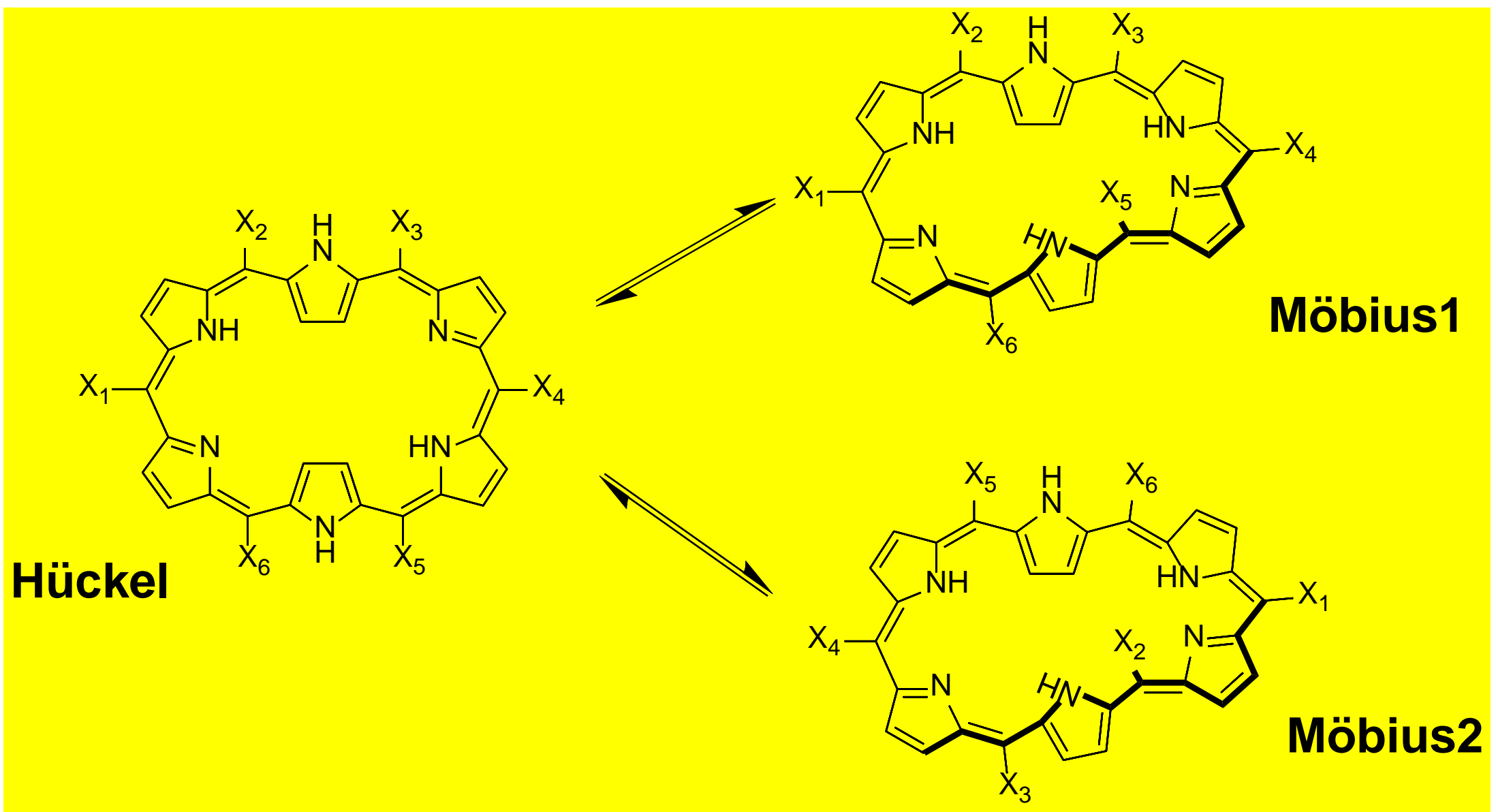

Scheme 1: Switching topology scheme between Hückel and Möbius conformers of the meso-substituted [28]hexaphyrins. For more details see Schemes 2-5. 

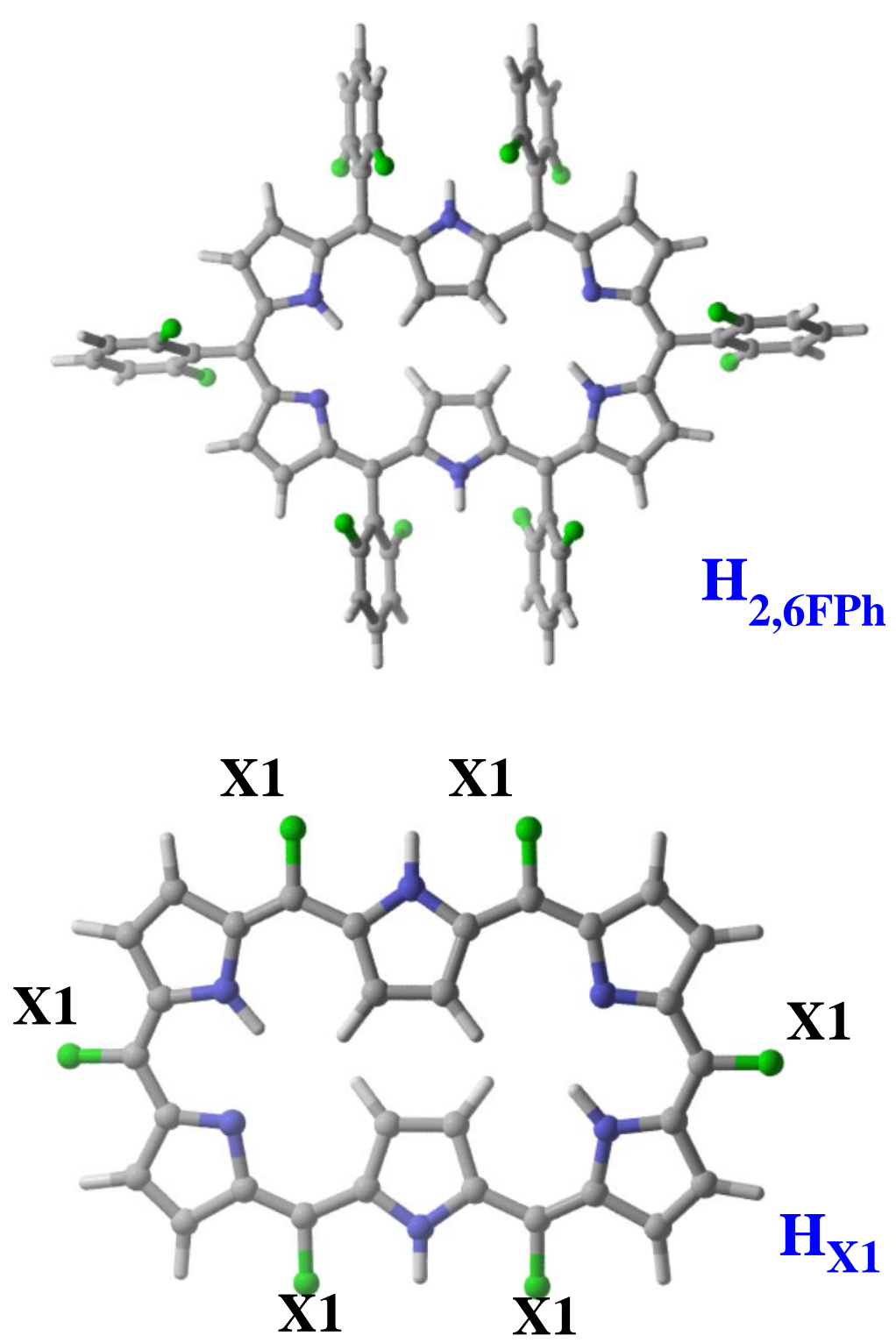

\section{$\mathrm{X1}=\mathrm{H}, \mathrm{F}, \mathrm{CH}_{3}$}

Scheme 2: Representation and nomenclature of Hückel and Möbius topologies of four different [28]hexaphyrins considered in this work. 


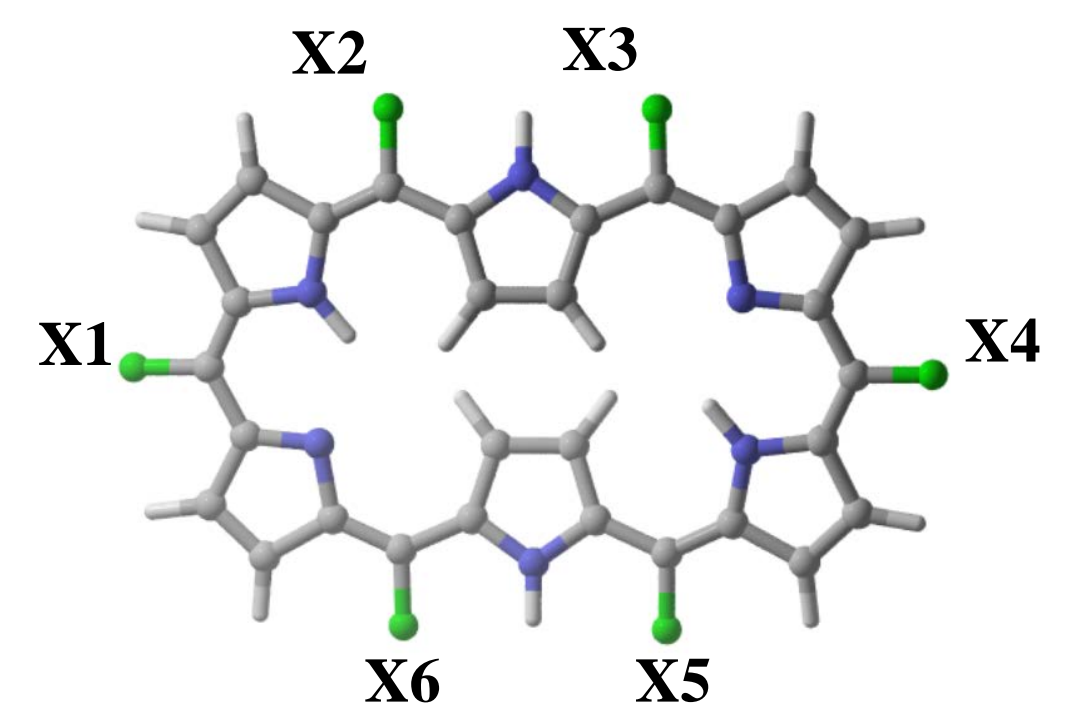

$\mathrm{H}_{\mathrm{CH} 3 \_\mathrm{F}_{-} \mathrm{a}} ; \mathrm{M}_{\mathrm{CH} 3 \_F_{-} \mathrm{a}}: \mathrm{X1}=\mathrm{CH}_{3}, \mathrm{X} 4=\mathrm{F}, \mathrm{X} 2=\mathrm{X3}=\mathrm{X} 5=\mathrm{X6}=\mathrm{H}$

$\mathrm{H}_{\text {CH3_F_b }} ; \mathrm{M1}_{\mathrm{CH} 3 \_F \_b}: \mathrm{X3}=\mathrm{CH}_{3}, \mathrm{X6}=\mathrm{F}, \mathrm{X} 1=\mathrm{X} 2=\mathrm{X} 4=\mathrm{X} 5=\mathrm{H}$ $\mathrm{M} 2_{\text {CH3_F_b }}: \mathrm{X} 3=\mathrm{F}, \mathrm{X6}=\mathrm{CH}_{3}, \mathrm{X1}=\mathrm{X} 2=\mathrm{X} 4=\mathrm{X} 5=\mathrm{H}$

$\mathrm{H}_{\mathrm{CH} 3 \_ \text {F_c }} ; \mathrm{M1}_{\text {CH3_F_c }}: \mathrm{X2}=\mathrm{X3}=\mathrm{X} 4=\mathrm{CH}_{3}, \mathrm{X1}=\mathrm{X} 5=\mathrm{X6}=\mathrm{F}$ $\mathrm{M} 2_{\text {CH3_F_c }}: \mathrm{X} 2=\mathrm{X} 3=\mathrm{X} 4=\mathrm{F}, \mathrm{X} 1=\mathrm{X} 5=\mathrm{X6}=\mathrm{CH}_{3}$

$\mathrm{H}_{\mathrm{CH} 3 \_\mathrm{F}_{-} \mathrm{d}} ; \mathrm{M}_{\mathrm{CH} 3 \_\mathrm{F} \_\mathrm{d}}: \mathrm{X} 2=\mathrm{X} 3=\mathrm{CH}_{3}, \mathrm{X} 5=\mathrm{X} 6=\mathrm{F}, \mathrm{X} 1=\mathrm{X} 4=\mathrm{H}$

$$
\mathrm{M} 2_{\text {CH3_F_d }}: \mathrm{X} 2=\mathrm{X} 3=\mathrm{F}, \mathrm{X} 5=\mathrm{X6}=\mathrm{CH}_{3}, \mathrm{X} 1=\mathrm{X} 4=\mathrm{H}
$$

Scheme 3: Representation and nomenclature of Hückel and Möbius topologies of eight different [28]hexaphyrins considered in this work.

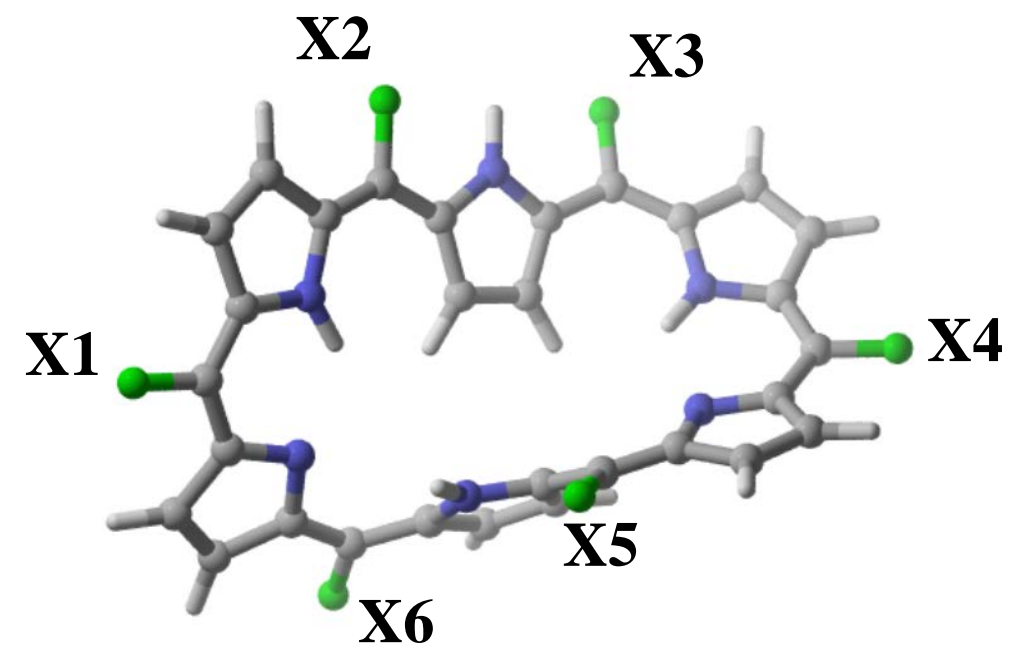

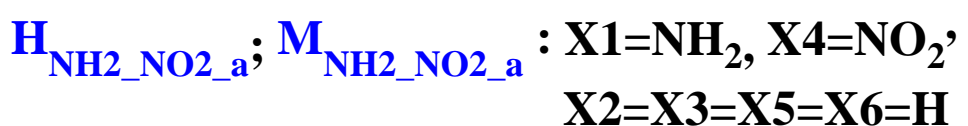
$\mathrm{H}_{\mathrm{NH} 2 \_\mathrm{NO2} \_\mathrm{b}} ; \mathrm{M1}_{\mathrm{NH} 2 \_\mathrm{NO2} \_\mathrm{b}}: \mathrm{X} 2=\mathrm{NH}_{2}, \mathrm{X} 5=\mathrm{NO}_{2}$, $\mathrm{X} 1=\mathrm{X3}=\mathrm{X} 4=\mathrm{X} 6=\mathrm{H}$ $\mathrm{M} 2_{\mathrm{NH} 2 \_\mathrm{NO2} \_\mathrm{b}}: \mathrm{X2}=\mathrm{NO}_{2}, \mathrm{X} 5=\mathrm{NH}_{2}, \mathrm{X} 1=\mathrm{X} 3=\mathrm{X} 4=\mathrm{X} 6=\mathrm{H}$

$\mathrm{H}_{\mathrm{NH} 2 \_\mathrm{NO} 2 \_\mathrm{c}} ; \mathrm{M1}_{\mathrm{NH2} \text { NO2_c }}: \mathrm{X2}=\mathrm{X} 3=\mathrm{X} 4=\mathrm{NH}_{2}$ $\mathrm{X} 1=\mathrm{X} 5=\mathrm{X6}=\mathrm{NO}_{2}$ $\mathrm{M} 2_{\mathrm{NH} 2 \_\mathrm{NO}_{2} \mathrm{C}}: \mathrm{X} 2=\mathrm{X} 3=\mathrm{X} 4=\mathrm{NO}_{2}, \mathrm{X} 1=\mathrm{X} 5=\mathrm{X6}=\mathrm{NH}_{2}$ $\mathrm{H}_{\mathrm{NH} 2 \text { NO2_d }} ; \mathrm{M1}_{\mathrm{NH2} \text { NO2_d }}: \mathrm{X} 2=\mathrm{X} 3=\mathrm{NH}_{2}, \mathrm{X} 5=\mathrm{X} 6=\mathrm{NO}_{2}$ $\mathrm{X} 1=\mathrm{X} 4=\mathrm{H}$ $\mathrm{M} 2_{\text {NH2_NO2_d }}: \mathrm{X2}=\mathrm{X3}=\mathrm{NO}_{2}, \mathrm{X} 5=\mathrm{X6}=\mathrm{NH}_{2}, \mathrm{X1}=\mathrm{X} 4=\mathrm{H}$ 

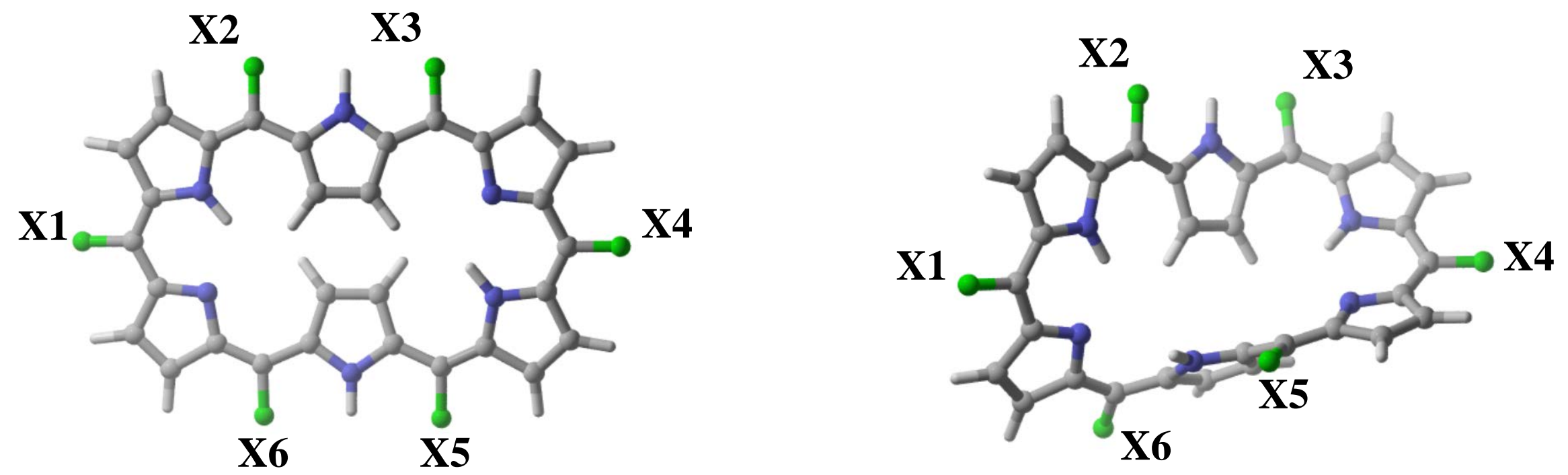

$\mathrm{H}_{\mathrm{PhNH2} \_\mathrm{PhNO2}} ; \mathrm{M}_{\mathrm{PhNH} 2 \_\mathrm{PhNO} 2}: \mathrm{X2}=\mathrm{X3}=\mathrm{X} 5=\mathrm{X6}=\mathrm{H}, \mathrm{X1}=$
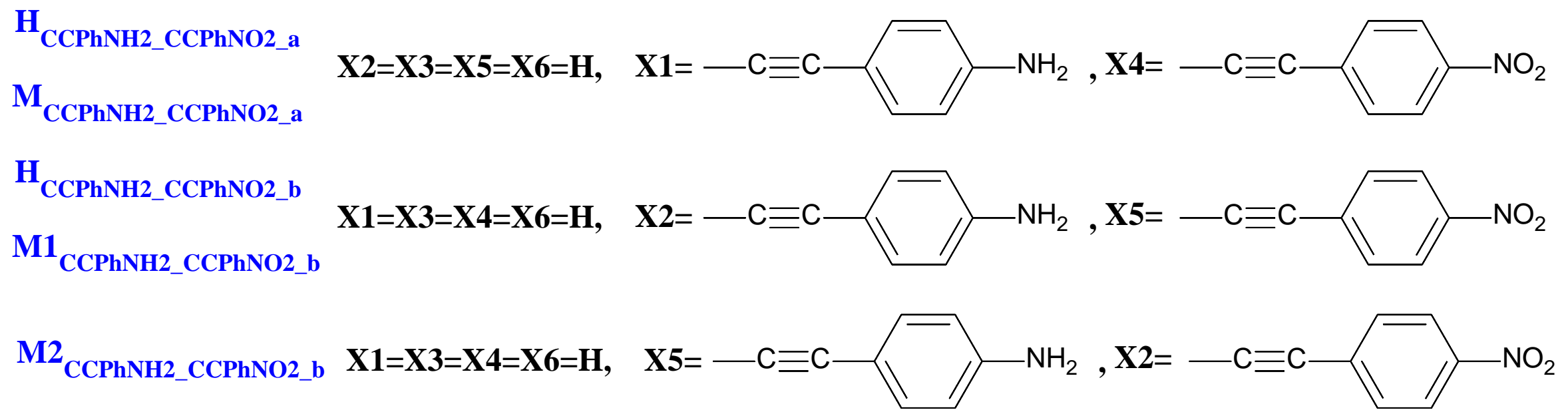

Scheme 4: Representation and nomenclature of Hückel and Möbius topologies of three different [28]hexaphyrins considered in this work. 

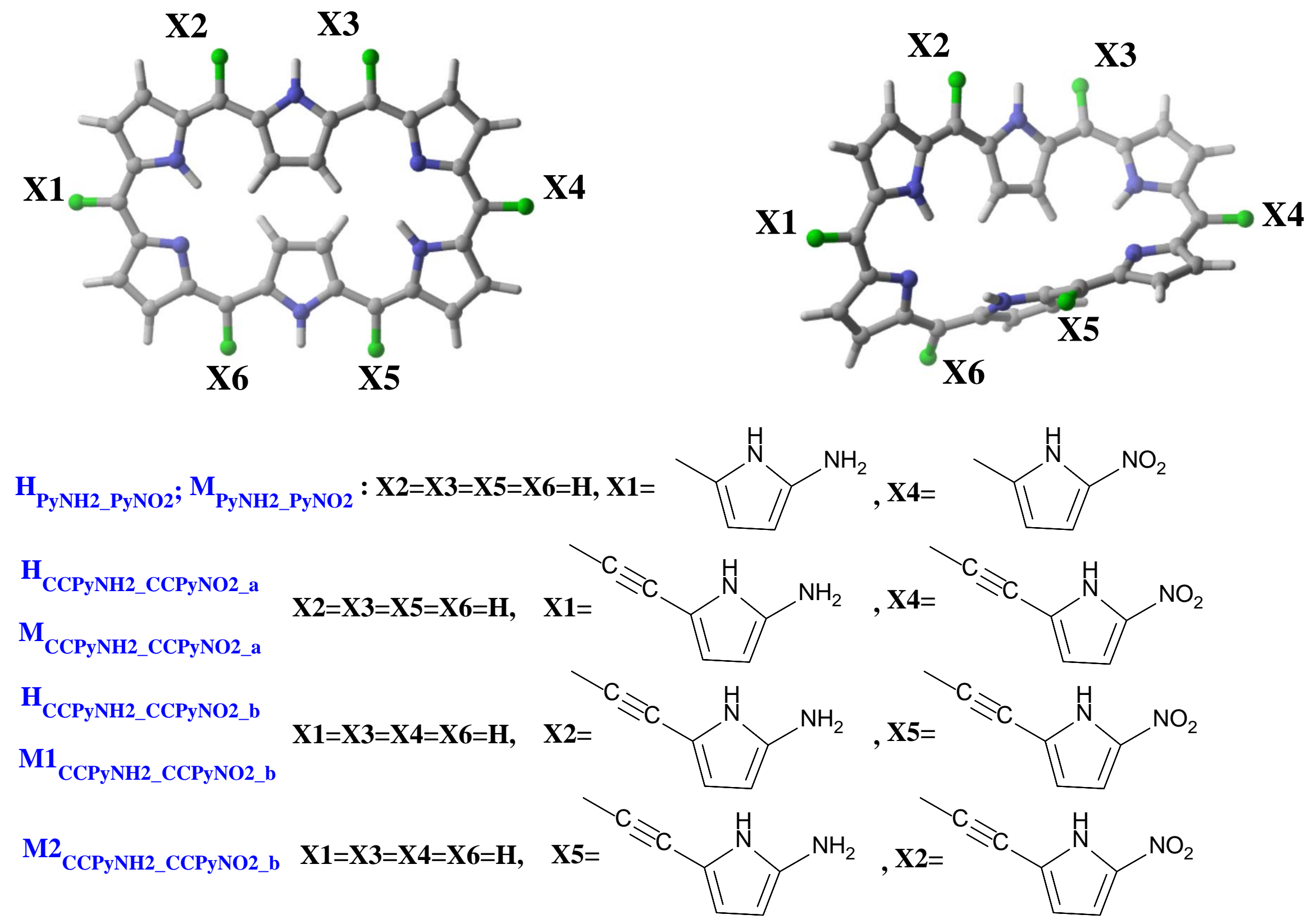

Scheme 5: Representation and nomenclature of Hückel and Möbius topologies of three different [28]hexaphyrins considered in this work. 
Table 1: Electronic and nuclear relaxation polarizabilities and first and second hyperpolarizabilities for the Hückel and Möbius topologies of meso-hexakis(2,6-difluorophenyl)[28]hexaphyrin(1.1.1.1.1.1) ( $\mathbf{H}_{2,6 \mathbf{F P h}}$ and $\mathbf{M}_{2,6 \mathbf{F P h}}$ ) calculated using 4 different levels of theory. All quantities are in atomic units.

\begin{tabular}{|c|c|c|c|c|c|c|c|c|}
\hline \multirow[b]{2}{*}{ Properties } & \multicolumn{2}{|c|}{ CAM-B3L YP/6-31G } & \multicolumn{2}{|c|}{ CAM-B3LYP/6-311G(d) } & \multicolumn{2}{|c|}{ CAM-B3LYP/6-31+G } & \multicolumn{2}{|c|}{ M05-2X/6-31G } \\
\hline & $\mathbf{H}_{2,6 \mathrm{FPh}}{ }^{\mathrm{a}}$ & $\mathbf{M}_{2,6 \mathrm{FPh}}$ & $\mathbf{H}_{2,6 F P h}{ }^{a}$ & $\mathbf{M}_{2,6 \mathrm{FPh}}$ & $\mathbf{H}_{2,6 \mathbf{F P h}}{ }^{\mathrm{a}, \mathrm{b}}$ & $\mathbf{M}_{2,6 \mathbf{F P h}}{ }^{\mathrm{b}}$ & $\mathbf{H}_{2,6 \mathbf{F P h}}{ }^{\mathrm{a}, \mathrm{b}}$ & $\mathbf{M}_{2,6 \mathbf{F P h}}{ }^{\mathrm{b}}$ \\
\hline $\bar{\alpha}^{e}(0 ; 0)$ & $9.63 \times 10^{2}$ & $9.75 \times 10^{2}$ & $1.02 \times 10^{3}$ & $1.00 \times 10^{3}$ & $1.06 \times 10^{3}$ & $1.05 \times 10^{3}$ & $9.56 \times 10^{2}$ & $9.81 \times 10^{2}$ \\
\hline $\bar{\alpha}^{n r}(0 ; 0)$ & $1.95 \times 10^{2}$ & $1.63 \times 10^{2}$ & $1.83 \times 10^{2}$ & $1.55 \times 10^{2}$ & $2.45 \times 10^{2}$ & $2.00 \times 10^{2}$ & $2.13 \times 10^{2}$ & $1.81 \times 10^{2}$ \\
\hline $\bar{\beta}^{e}(0 ; 0,0)$ & $0.00 \times 10^{0}$ & $1.38 \times 10^{3}$ & $0.00 \times 10^{0}$ & $1.13 \times 10^{3}$ & $0.00 \times 10^{0}$ & $1.47 \times 10^{3}$ & $0.00 \times 10^{0}$ & $1.26 \times 10^{3}$ \\
\hline $\bar{\beta}^{n r}(0 ; 0,0)$ & $0.00 \times 10^{0}$ & $2.26 \times 10^{3}$ & $0.00 \times 10^{0}$ & $3.68 \times 10^{2}$ & & & & \\
\hline $\bar{\beta}^{\mathrm{nr}}(-\omega ; \omega, 0)_{\omega \rightarrow \infty}$ & $0.00 \times 10^{0}$ & $2.50 \times 10^{3}$ & $0.00 \times 10^{0}$ & $1.87 \times 10^{3}$ & $0.00 \times 10^{0}$ & $1.88 \times 10^{3}$ & $0.00 \times 10^{0}$ & $2.91 \times 10^{3}$ \\
\hline $\bar{\gamma}^{e}(0 ; 0,0,0)$ & $1.29 \times 10^{6}$ & $1.39 \times 10^{6}$ & $1.21 \times 10^{6}$ & $1.32 \times 10^{6}$ & $1.42 \times 10^{6}$ & $1.53 \times 10^{6}$ & $1.36 \times 10^{6}$ & $1.41 \times 10^{6}$ \\
\hline $\bar{\gamma}^{n r}(-\omega ; \omega, 0,0)_{\omega \rightarrow \infty}^{\mathrm{c}, \mathrm{d}}$ & $8.59 \times 10^{5}$ & $1.21 \times 10^{6}$ & $8.95 \times 10^{5}$ & $1.19 \times 10^{6}$ & & & & \\
\hline $\bar{\gamma}^{n r}(-2 \omega ; \omega, \omega, 0)_{\omega \rightarrow \infty}$ & $-1.44 \times 10^{5}$ & $-1.95 \times 10^{5}$ & $-1.25 \times 10^{5}$ & $-1.85 \times 10^{5}$ & & & & \\
\hline $\bar{\gamma}^{n r}(-\omega ; \omega,-\omega, \omega)_{\omega \rightarrow \infty}{ }^{\mathrm{c}}$ & $1.84 \times 10^{6}$ & $3.69 \times 10^{6}$ & $2.27 \times 10^{6}$ & $3.53 \times 10^{6}$ & $2.05 \times 10^{6}$ & $3.91 \times 10^{6}$ & $1.73 \times 10^{6}$ & $3.81 \times 10^{6}$ \\
\hline $\begin{array}{l}\text { a } \bar{\beta}^{e}(0 ; 0,0), \bar{\beta}^{n r}(0 ; 0,0) \\
\bar{\gamma}^{n r}(-2 \omega ; \omega, \omega, 0)_{\omega \rightarrow \infty} \text { prop } \\
\text { normal modes instead of } t \\
\text { elements of the hyperpola } \\
\text { components are approxima }\end{array}$ & and $\bar{\beta}^{\mathrm{nr}}($ & $\begin{array}{l}, 0)_{\omega \rightarrow \infty} \\
\text { een evalua } \\
\text { and harmo }\end{array}$ & perties ar & $\left.\chi_{2, h a r}^{\alpha \alpha}\right) \mathrm{FI}$ & $\begin{array}{l}\text { etry. } \\
\text { al effort. }\end{array}$ & s of $\gamma_{a b b}^{n r}$ & value for & $\begin{array}{l})_{\omega \rightarrow \infty} \text {, and } \\
\text { using } 3 N-6 \\
\text { on-diagonal } \\
\text { on-diagonal } \\
\text {, and } \chi_{2, \text { har }}^{y z}\end{array}$ \\
\hline
\end{tabular}


Table 2: Electronic and nuclear relaxation polarizabilities and first and second hyperpolarizabilities for the Hückel and Möbius topologies of seven different [28]hexaphyrin (H, F, CH3, CH3_F_a, CH3_F_b, CH3_F_c, and CH3_F_d) evaluated at the M05-2X/6-31G level of theory. All quantities are in atomic units.

\begin{tabular}{|c|c|c|c|c|c|c|}
\hline Subst. $^{\mathrm{a}}$ & $\bar{\alpha}^{e}(0 ; 0)$ & $\bar{\alpha}^{n r}(0 ; 0)$ & $\bar{\beta}^{e}(0 ; 0,0)^{\mathrm{b}}$ & $\bar{\beta}^{n r}(-\omega ; \omega, 0)_{\omega \rightarrow \infty} \mathrm{b}$ & $\bar{\gamma}^{e}(0 ; 0,0,0)$ & $\bar{\gamma}^{n r}(-\omega ; \omega,-\omega, \omega)_{\omega \rightarrow \infty}{ }^{c}$ \\
\hline Нн & $5.28 \times 10^{2}$ & $7.87 \times 10^{1}$ & $0.00 \times 10^{0}$ & $0.00 \times 10^{0}$ & $5.59 \times 10^{5}$ & $7.58 \times 10^{5}$ \\
\hline $\mathbf{M}_{\mathbf{H}}$ & $5.31 \times 10^{2}$ & $5.14 \times 10^{1}$ & $7.33 \times 10^{2}$ & $8.10 \times 10^{2}$ & $4.48 \times 10^{5}$ & $1.71 \times 10^{6}$ \\
\hline $\mathbf{H}_{\mathbf{F}}$ & $5.25 \times 10^{2}$ & $7.22 \times 10^{1}$ & $0.00 \times 10^{0}$ & $0.00 \times 10^{0}$ & $7.25 \times 10^{5}$ & $7.65 \times 10^{5}$ \\
\hline $\mathbf{M F}_{\mathbf{F}}$ & $5.29 \times 10^{2}$ & $5.18 \times 10^{1}$ & $2.36 \times 10^{3}$ & $9.19 \times 10^{2}$ & $6.27 \times 10^{5}$ & $1.75 \times 10^{6}$ \\
\hline $\mathbf{H}_{\mathrm{CH} 3}$ & $6.17 \times 10^{2}$ & $2.00 \times 10^{2}$ & $0.00 \times 10^{0}$ & $0.00 \times 10^{0}$ & $8.15 \times 10^{5}$ & $1.06 \times 10^{6}$ \\
\hline МсH3 & $6.18 \times 10^{2}$ & $5.88 \times 10^{1}$ & $1.55 \times 10^{3}$ & $1.41 \times 10^{3}$ & $5.92 \times 10^{5}$ & $2.23 \times 10^{6}$ \\
\hline НСH3_F_a & $5.57 \times 10^{2}$ & $9.12 \times 10^{1}$ & $1.23 \times 10^{3}$ & $1.17 \times 10^{3}$ & $6.67 \times 10^{5}$ & $8.75 \times 10^{5}$ \\
\hline MCH3_F_a & $5.54 \times 10^{2}$ & $6.19 \times 10^{1}$ & $1.24 \times 10^{3}$ & $1.67 \times 10^{3}$ & $5.47 \times 10^{5}$ & $1.48 \times 10^{6}$ \\
\hline HCH3_F_b & $5.36 \times 10^{2}$ & $7.36 \times 10^{1}$ & $1.91 \times 10^{1}$ & $2.13 \times 10^{2}$ & $6.02 \times 10^{5}$ & $6.91 \times 10^{5}$ \\
\hline M1CH3_F_b & $5.38 \times 10^{2}$ & $5.33 \times 10^{1}$ & $1.20 \times 10^{3}$ & $1.29 \times 10^{3}$ & $5.34 \times 10^{5}$ & $1.55 \times 10^{6}$ \\
\hline M2CH3_F_b & $5.35 \times 10^{2}$ & $5.33 \times 10^{1}$ & $-1.04 \times 10^{3}$ & $-5.27 \times 10^{2}$ & $5.40 \times 10^{5}$ & $1.47 \times 10^{6}$ \\
\hline HCH3_F_c & $5.71 \times 10^{2}$ & $7.78 \times 10^{1}$ & $9.10 \times 10^{2}$ & $5.93 \times 10^{2}$ & $7.72 \times 10^{5}$ & $8.81 \times 10^{5}$ \\
\hline M1CH3_F_c & $5.78 \times 10^{2}$ & $5.72 \times 10^{1}$ & $3.53 \times 10^{3}$ & $2.68 \times 10^{3}$ & $6.21 \times 10^{5}$ & $2.06 \times 10^{6}$ \\
\hline M2CH3_F_c & $5.67 \times 10^{2}$ & $5.40 \times 10^{1}$ & $-2.60 \times 10^{3}$ & $-1.64 \times 10^{3}$ & $5.97 \times 10^{5}$ & $1.81 \times 10^{6}$ \\
\hline HCH3_F_d & $5.44 \times 10^{2}$ & $6.61 \times 10^{1}$ & $4.56 \times 10^{1}$ & $2.22 \times 10^{2}$ & $6.26 \times 10^{5}$ & $6.79 \times 10^{5}$ \\
\hline M1CH3_F_d & $5.40 \times 10^{2}$ & $5.41 \times 10^{1}$ & $1.98 \times 10^{3}$ & $1.25 \times 10^{3}$ & $6.09 \times 10^{5}$ & $1.53 \times 10^{6}$ \\
\hline M2CH3_F_d & $5.38 \times 10^{2}$ & $5.14 \times 10^{1}$ & $-2.49 \times 10^{3}$ & $-8.69 \times 10^{2}$ & $5.68 \times 10^{5}$ & $1.41 \times 10^{6}$ \\
\hline
\end{tabular}

${ }^{\text {a }}$ For more details of the used nomenclature see Scheme $1 .{ }^{\mathrm{b}}$ Some $\bar{\beta}^{e}(0 ; 0,0)$ and $\bar{\beta}^{n r}(-\omega ; \omega, 0)_{\omega \rightarrow \infty}$ properties of the Hückel conformations are null by symmetry. ${ }^{\mathrm{c}}$ The $\left[\alpha^{2}\right]$ terms were calculated using $3 N-6$ normal modes instead of the six first $\left(\chi_{1}^{\alpha}\right)$ and harmonic second-order $\left(\chi_{2, \text { har }}^{\alpha \alpha}\right)$ FICs in order to obtain the correct value for the non-diagonal elements of the hyperpolarizabilities tensor (see Table I of Ref. 88 for more details). 
Table 3: Electronic and nuclear relaxation polarizabilities and first and second hyperpolarizabilities for the Hückel and Möbius topologies of a [28]hexaphyrin with amino and nitro groups as meso-substituents located in four different distributions around the expanded porphyrin calculated using the 6-31G and 6-311G(d) basis sets ${ }^{\mathrm{b}}$ and the M05-2X functional. All quantities are in atomic units.

\begin{tabular}{|c|c|c|c|c|c|c|}
\hline Subst. ${ }^{a}$ & $\bar{\alpha}^{e}(0 ; 0)$ & $\bar{\alpha}^{n r}(0 ; 0)$ & $\bar{\beta}^{e}(0 ; 0,0)$ & $\bar{\beta}^{n r}(-\omega ; \omega, 0)_{\omega \rightarrow \infty}$ & $\bar{\gamma}^{e}(0 ; 0,0,0)$ & $\bar{\gamma}^{n r}(-\omega ; \omega,-\omega, \omega)_{\omega \rightarrow \infty}{ }^{c}$ \\
\hline $\mathbf{M}_{\text {NH2_NO2_a }}$ & $\begin{array}{c}5.94 \times 10^{2} \\
\left(5.99 \times 10^{2}\right) \\
6.31 \times 10^{2} \\
\left(6.05 \times 10^{2}\right)\end{array}$ & $\begin{array}{c}2.25 \times 10^{2} \\
\left(2.31 \times 10^{2}\right) \\
1.70 \times 10^{2} \\
\left(1.56 \times 10^{2}\right)\end{array}$ & $\begin{array}{c}7.89 \times 10^{3} \\
\left(4.28 \times 10^{3}\right) \\
7.71 \times 10^{3} \\
\left(5.88 \times 10^{3}\right)\end{array}$ & $\begin{array}{c}6.84 \times 10^{3} \\
\left(5.91 \times 10^{3}\right) \\
1.70 \times 10^{4} \\
\left(1.19 \times 10^{4}\right)\end{array}$ & $\begin{array}{c}9.42 \times 10^{5} \\
\left(7.13 \times 10^{5}\right) \\
3.83 \times 10^{5} \\
\left(3.80 \times 10^{5}\right)\end{array}$ & $\begin{array}{c}1.28 \times 10^{6} \\
\left(1.10 \times 10^{6}\right) \\
2.97 \times 10^{6} \\
\left(2.55 \times 10^{6}\right)\end{array}$ \\
\hline $\mathrm{H}_{\mathrm{NH} 2 \_N O 2 \_b}$ & $5.83 \times 10^{2}$ & $1.82 \times 10^{2}$ & $4.98 \times 10^{3}$ & $7.01 \times 10^{3}$ & $9.81 \times 10^{5}$ & $1.48 \times 10^{6}$ \\
\hline M1NH2_NO2_b & $5.71 \times 10^{2}$ & $1.36 \times 10^{2}$ & $2.47 \times 10^{3}$ & $3.46 \times 10^{3}$ & $7.20 \times 10^{5}$ & $1.57 \times 10^{6}$ \\
\hline M2_NH2_NO2_b & $5.88 \times 10^{2}$ & $1.61 \times 10^{2}$ & $-3.13 \times 10^{3}$ & $4.79 \times 10^{2}$ & $5.35 \times 10^{5}$ & $3.56 \times 10^{6}$ \\
\hline HNH2_NO2_c & $6.46 \times 10^{2}$ & $3.44 \times 10^{2}$ & $8.70 \times 10^{1}$ & $3.83 \times 10^{3}$ & $6.88 \times 10^{5}$ & $1.68 \times 10^{6}$ \\
\hline M1 NH2_NO2_c & $6.66 \times 10^{2}$ & $2.74 \times 10^{2}$ & $1.56 \times 10^{3}$ & $3.44 \times 10^{3}$ & $1.19 \times 10^{5}$ & $1.81 \times 10^{6}$ \\
\hline M2NH2_NO2_c & $6.00 \times 10^{2}$ & $2.00 \times 10^{2}$ & $3.24 \times 10^{3}$ & $7.79 \times 10^{3}$ & $1.34 \times 10^{6}$ & $2.36 \times 10^{6}$ \\
\hline $\mathbf{H}_{\mathrm{NH} 2 \text { _NO2_d }}$ & $5.90 \times 10^{2}$ & $1.73 \times 10^{2}$ & $3.12 \times 10^{3}$ & $5.22 \times 10^{3}$ & $6.41 \times 10^{5}$ & $1.43 \times 10^{6}$ \\
\hline M1NH2_NO2_d & $6.24 \times 10^{2}$ & $2.21 \times 10^{2}$ & $1.41 \times 10^{3}$ & $1.60 \times 10^{3}$ & $1.39 \times 10^{5}$ & $1.28 \times 10^{6}$ \\
\hline M2_NH2_NO2_d & $5.39 \times 10^{2}$ & $1.40 \times 10^{2}$ & $-7.25 \times 10^{3}$ & $5.59 \times 10^{3}$ & $6.50 \times 10^{5}$ & $1.27 \times 10^{6}$ \\
\hline
\end{tabular}

${ }^{a}$ For more details of the used nomenclature see Scheme $2 .{ }^{b}$ The values with the $6-311 G(d)$ basis set are in parenthesis. ${ }^{c}$ The $\left[\alpha^{2}\right]$ terms were calculated using 3N-6 normal modes instead of the six first $\left(\chi_{1}^{\alpha}\right)$ and harmonic second-order $\left(\chi_{2, \text { har }}^{\alpha \alpha}\right)$ FICs in order to obtain the correct value for the non-diagonal elements of the hyperpolarizabilities tensor (see Table I of Ref. 88 for more details). 
Table 4: Electronic and nuclear relaxation polarizabilities and first and second hyperpolarizabilities for the Hückel and Möbius topologies of six [28]hexaphyrin with different push-pull meso-substituents located in two different distributions around the expanded porphyrin calculated using the 6-31G and 6-311G(d) basis sets ${ }^{\mathrm{b}}$ and the M05-2X functional. All quantities are in atomic units.

\begin{tabular}{|c|c|c|c|c|c|c|}
\hline Subst. $^{\mathrm{a}}$ & $\bar{\alpha}^{e}(0 ; 0)$ & $\bar{\alpha}^{n r}(0 ; 0)$ & $\bar{\beta}^{e}(0 ; 0,0)^{\mathrm{c}}$ & $\bar{\beta}^{n r}(-\omega ; \omega, 0)_{\omega \rightarrow \infty}$ & $\bar{\gamma}^{e}(0 ; 0,0,0)$ & $\bar{\gamma}^{n r}(-\omega ; \omega,-\omega, \omega)_{\omega \rightarrow \infty}^{c}$ \\
\hline HPhNH2_PhNO2 & $7.89 \times 10^{2}$ & $1.79 \times 10^{2}$ & $2.08 \times 10^{4}$ & $7.85 \times 10^{3}$ & $3.62 \times 10^{6}$ & $2.49 \times 10^{6}$ \\
\hline MPhNH2_PhNO2 & $8.19 \times 10^{2}$ & $1.38 \times 10^{2}$ & $2.15 \times 10^{4}$ & $1.47 \times 10^{4}$ & $3.50 \times 10^{6}$ & $5.74 \times 10^{6}$ \\
\hline MCCPhNH2_CCPhNO2_a & $\begin{array}{c}9.72 \times 10^{2} \\
\left(9.81 \times 10^{2}\right) \\
9.84 \times 10^{2} \\
\left(9.78 \times 10^{2}\right)\end{array}$ & $\begin{array}{c}2.52 \times 10^{2} \\
\left(2.61 \times 10^{2}\right) \\
1.92 \times 10^{2} \\
\left(2.24 \times 10^{2}\right)\end{array}$ & $\begin{array}{c}5.05 \times 10^{4} \\
\left(3.06 \times 10^{3}\right) \\
4.77 \times 10^{4} \\
\left(2.83 \times 10^{3}\right)\end{array}$ & $\begin{array}{c}1.01 \times 10^{4} \\
\left(3.83 \times 10^{3}\right) \\
2.28 \times 10^{4} \\
\left(1.93 \times 10^{4}\right)\end{array}$ & $\begin{array}{c}9.73 \times 10^{6} \\
\left(6.13 \times 10^{5}\right) \\
9.73 \times 10^{6} \\
\left(6.54 \times 10^{5}\right)\end{array}$ & $\begin{array}{c}5.23 \times 10^{6} \\
\left(5.23 \times 10^{6}\right) \\
1.09 \times 10^{7} \\
\left(9.44 \times 10^{6}\right)\end{array}$ \\
\hline HCCPhNH2_CCPhNO2_b & $8.90 \times 10^{2}$ & $1.99 \times 10^{2}$ & $3.59 \times 10^{4}$ & $1.13 \times 10^{4}$ & $6.14 \times 10^{6}$ & $4.64 \times 10^{6}$ \\
\hline M1CCPhNH2_CCPhNO2_b & $8.20 \times 10^{2}$ & $2.10 \times 10^{2}$ & $1.15 \times 10^{4}$ & $1.95 \times 10^{4}$ & $2.09 \times 10^{6}$ & $6.58 \times 10^{6}$ \\
\hline M2CCPhNH2_CCPhNO2_b & $8.64 \times 10^{2}$ & $2.89 \times 10^{2}$ & $2.04 \times 10^{4}$ & $3.08 \times 10^{4}$ & $3.87 \times 10^{6}$ & $9.96 \times 10^{6}$ \\
\hline НPyNH2_PyNO2 & $7.48 \times 10^{2}$ & $2.01 \times 10^{2}$ & $1.27 \times 10^{4}$ & $9.48 \times 10^{3}$ & $2.33 \times 10^{6}$ & $2.51 \times 10^{6}$ \\
\hline MPyNH2_PyNO2 & $7.93 \times 10^{2}$ & $1.80 \times 10^{2}$ & $1.52 \times 10^{4}$ & $2.14 \times 10^{4}$ & $2.68 \times 10^{6}$ & $7.69 \times 10^{6}$ \\
\hline HCCPyNH2_CCPyNO2_a & $8.89 \times 10^{2}$ & $6.00 \times 10^{2}$ & $2.47 \times 10^{4}$ & $1.35 \times 10^{4}$ & $5.11 \times 10^{6}$ & $6.63 \times 10^{6}$ \\
\hline MCCPyNH2_CCPyNO2_a & $9.21 \times 10^{2}$ & $4.12 \times 10^{2}$ & $3.09 \times 10^{4}$ & $3.37 \times 10^{4}$ & $6.73 \times 10^{6}$ & $1.21 \times 10^{7}$ \\
\hline НCCPyNH2_CCPyNO2_b & $8.27 \times 10^{2}$ & $5.62 \times 10^{2}$ & $1.75 \times 10^{4}$ & $4.37 \times 10^{4}$ & $3.43 \times 10^{6}$ & $9.96 \times 10^{6}$ \\
\hline M1_CPyNH2_CCPyNO2_b & $7.92 \times 10^{2}$ & $3.94 \times 10^{2}$ & $1.35 \times 10^{4}$ & $1.70 \times 10^{4}$ & $2.17 \times 10^{6}$ & $6.79 \times 10^{6}$ \\
\hline M2_CPyNH2_CCPyNO2_b & $8.11 \times 10^{2}$ & $4.23 \times 10^{2}$ & $3.90 \times 10^{3}$ & $9.70 \times 10^{3}$ & $1.85 \times 10^{6}$ & $1.01 \times 10^{7}$ \\
\hline
\end{tabular}

${ }^{a}$ For more details of the used nomenclature see Scheme 3. ${ }^{\mathrm{b}}$ The values with the $6-311 \mathrm{G}(\mathrm{d})$ basis set are in parenthesis. ${ }^{\mathrm{c}}$ The $\left[\alpha^{2}\right]$ terms were calculated using $3 N-6$ normal modes instead of the six first $\left(\chi_{1}^{\alpha}\right)$ and harmonic second-order $\left(\chi_{2, \text { har }}^{\alpha \alpha}\right)$ FICs in order to obtain the correct value for the non-diagonal elements of the hyperpolarizabilities tensor (see Table I of Ref. 88 for more details). 
TOC Graphic

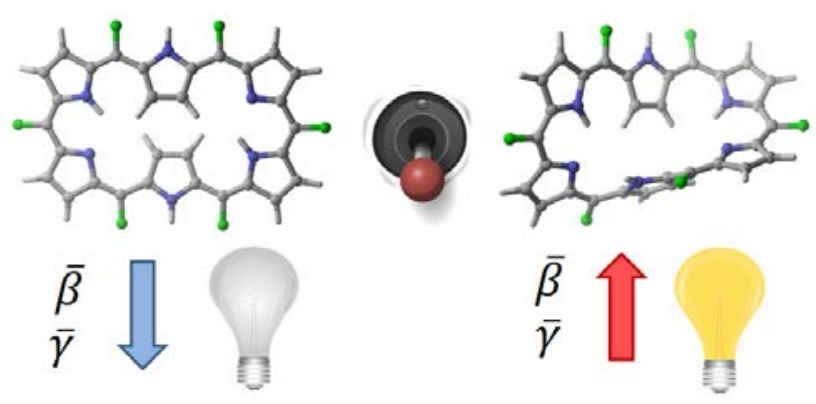

